Revista lus et Praxis, Año 25, № 2, 2019, pp. 359 - 402

ISSN 0717 - 2877

Universidad de Talca - Facultad de Ciencias Jurídicas y Sociales

Identidad de género de niños, niñas y adolescentes:

Una cuestión de derechos

Ximena A. Gauché Marchetti - Domingo A. Lovera Parmo

Trabajo recibido el 24 de enero de 2018 y aprobado el 19 de diciembre de 2018

\title{
Identidad de género de niños, niñas y adolescentes: Una cuestión de derechos
}

\section{GENDER IDENTITY OF CHILDREN AND ADOLESCENTS: A MATTER OF RIGHTS}

\author{
Ximena A. Gauché Marchetti* \\ Domingo A. Lovera Parmo**
}

\begin{abstract}
RESUMEN
Este trabajo tiene por objeto defender el derecho fundamental de niños, niñas y adolescentes (NNA) a su identidad de género. Afirmamos que los NNA gozan de un derecho constitucional a la autodeterminación de género, el que encuentra reconocimiento también en el derecho internacional de los derechos humanos. Tratándose de un derecho constitucional, los NNA son titulares de ese derecho y gozan de autonomía progresiva para efectos de su ejercicio. Nos distanciamos así de posturas que asumen la situación de los NNA como una de carácter eminentemente médico o patológico - postura que ha encontrado fuerte eco en nuestra jurisprudencia-, en los casos en que ellos expresan o reclaman su propia identidad, o como un asunto en que son los padres y madres o adultos responsables quienes deben intervenir, excluyéndolos de la definición de esta identidad.
\end{abstract}

\section{ABSTRACT}

This paper defends the fundamental right of children and adolescents to gender identity. We contend that children and adolescents are constitutionally entitled to autonomously determine their gender identity, a right which is also recognized in the international human rights law. As bearers of constitutional rights, children and adolescents can autonomously exercise their right to gender identity in accordance with their age and maturity. We then take distance from those approaches which either hold that children are incapable of autonomous exercise of rights, being a decision to be taken by their parents or any other responsible adult, or that see gender identity issues as medical or pathological matters -an approach that our jurisprudence has mistakenly endorsed-.

PALABRAS CLAVES

Identidad de género; autonomía; niño, niñas y adolescentes

\footnotetext{
* Doctora en Derecho, Universidad Autónoma de Madrid. Profesora asociada de Derecho Internacional y Derechos Fundamentales en la Facultad de Ciencias Jurídicas y Sociales de la Universidad de Concepción (Chile), Departamento de Derecho Público, Facultad de Ciencias Jurídicas y Sociales, Universidad de Concepción. Dirección: Barrio Universitario s/n, Concepción. 5641 220387. Correo electrónico: xgauche@udec.cl; xgauche@gmail.com.

** LI.M. Columbia University, Ph.D., York University, Canadá. Profesor asistente en la Facultad de Derecho Universidad Diego Portales (Chile). Dirección: Avenida República 112, Región Metropolitana, Santiago. Correo electrónico: domingo.lovera@udp.cl.
} 
KEY WORDS

Gender identity; autonomy; children and adolescents

\section{Introducción}

Para situar la discusión que este artículo plantea, aunque sin agotarla, nos centramos en el debate que se ha trabado en el Congreso Nacional con relación a dos proyectos legislativos en el que ambos autores hemos tenido ocasión de intervenir. Como se verá, el nuestro es un reclamo de comprensión constitucional que, más que prestar atención al desarrollo jurisprudencial (al que se aludirá, sin embargo, más abajo), se centrará en el debate mencionado, a propósito de la tramitación legislativa del Proyecto de Ley de Sistema de Garantías de los Derechos de la Niñez (en adelante, el proyecto de ley de garantías) ${ }^{1}$ y del Proyecto de Ley que Reconoce y da Protección al Derecho a la Identidad de Género $^{2}$ (en adelante, el proyecto de identidad de género).

Como se conoce, en los términos del texto original del proyecto de ley de garantías, la expresión "identidad de género" aparece en al art. $8^{\circ}$, inc. $2^{\circ}$, del mismo, a propósito del reconocimiento del derecho a la igualdad y no discriminación:

Ningún niño podrá ser discriminado en forma arbitraria en razón de su raza, etnia, nacionalidad, cultura, estatus migratorio, carácter de refugiado o asilado, idioma, opinión política o ideología, afiliación o asociación, religión o creencia, situación socioeconómica, sexo, orientación sexual, identidad de género, expresión de género, características sexuales; estado civil, edad, filiación, apariencia personal, salud, discapacidad o en situación de discapacidad, estar o haber sido imputado, acusado o condenado por aplicación de la Ley $N^{\circ} 20.084$, o en razón de cualquier otra condición, actividad o estatus suyo o de sus padres, familia, representantes legales o quienes lo tengan bajo su cuidado.

Si bien en el texto original del proyecto la expresión "identidad de género" está ausente del reconocimiento del derecho a la identidad de los

${ }^{1}$ Boletín No 10315-18.

2 Boletín No 8924-07. 
NNA ${ }^{3}$, una indicación de S. E. la presidenta de la República de la época sugiere salvar esta ausencia ${ }^{4}$.

Por su parte, en el proyecto de identidad de género, los NNA han sido incluidos y excluidos como titulares del derecho a la identidad de género. Incluidos en el origen del proyecto para poder solicitar el reconocimiento de su identidad de género, fueron posteriormente excluidos al momento de ingresar el proyecto e iniciar la discusión legislativa en mayo de 2013, teniendo una larga y compleja historia ${ }^{5}$. Al momento en que se termina de escribir este trabajo, el proyecto de identidad de género acaba de ser promulgado, quedando incluidos

\footnotetext{
${ }^{3}$ El texto original del proyecto dispone:
}

Artículo 12.- Derecho a la identidad. Todo niño tiene derecho, desde su nacimiento, a tener un nombre, una nacionalidad y una lengua de origen; a conocer la identidad de sus padres; a preservar sus relaciones familiares de conformidad con la ley; a conocer y ejercer la cultura de su lugar de origen $y$, en general, a preservar y desarrollar su propia identidad e idiosincrasia.

Los niños que pertenezcan a colectivos étnicos, indígenas, religiosos o lingüísticos tienen derecho, en común con los demás miembros de su grupo, a tener su propia vida cultural, a profesar y practicar su propia religión, a emplear su propio idioma, y a intervenir en los procedimientos de consulta cuando lo establezca la ley.

El Servicio de Registro Civil e Identificación dispondrá de procedimientos sencillos y rápidos que permitan la inscripción de nacimiento de los recién nacidos y su identificación oportuna, con independencia de su estatus migratorio o del de sus padres. En el caso que se desconozca la identidad de los progenitores del niño, éste deberá ser registrado con nombre y dos apellidos convencionales, dejándose constancia en la partida correspondiente, y sin perjuicio del derecho a reclamar posteriormente la determinación de su identidad.

${ }^{4}$ Ses. 113 a/363, de 5 de enero de 2016. Indica, así, intercalar la expresión "incluida su identidad de género" a continuación de la palabra "idiosincrasia".

${ }^{5}$ El 10 de marzo de 2014, la honorable senadora Lily Pérez San Martín introdujo varias indicaciones, entre ellas la número 17, para intercalar un nuevo artículo, a continuación del artículo $7^{\circ}$ original. El texto de esa indicación disponía lo siguiente:

"Artículo....- De la solicitud presentada por el niño, niña o adolescente. En el caso de las personas menores de dieciocho años de edad cuyo nacimiento se encuentre inscrito en Chile, la solicitud a que se refiere la presente ley podrá ser efectuada a través de sus representantes legales o quien lo tenga bajo su cuidado, y con el expreso consentimiento del niño, niña o adolescente o, personalmente, debiendo el tribunal en este caso, ordenar la comparecencia de éstos.

Será competente, en estos casos, el Juez de Familia del lugar donde tenga domicilio el niño, niña o adolescente a cuyo nombre se realiza la gestión o quien la interpone personalmente, y el procedimiento se sujetará, en lo que corresponda, a las disposiciones sobre actos judiciales no contenciosos del artículo 102 de la Ley No 19.968, que crea los tribunales de familia, y, en lo no previsto, por lo que dispone la presente ley.

Recibida la solicitud, el juez deberá oír al niño, niña o adolescente, velando en todo momento por la adecuada protección de su interés superior.

Oído el niño, niña o adolescente, el Tribunal podrá, por resolución fundada, ordenar o rechazar la designación de un Curador Ad Litem para que vele por su representación e intereses durante la tramitación de la solicitud. En todo caso, de efectuar personalmente la solicitud el niño, niña o adolescente o existir oposición de los representantes legales o quien lo tenga bajo su cuidado a la solicitud interpuesta por el menor de edad, el tribunal deberá siempre nombrársele un Curador Ad Litem. 
los NNA mayores de 14 años y menores de 18 años (aunque supeditados a que el procedimiento de rectificación sea iniciado por sus representantes legales o alguno de ellos), pero siendo excluidos niños y niñas menores de 14 años.

Esto nos parece un desconocimiento de los derechos constitucionales de los NNA. Nuestra opinión es que tales proyectos deben reconocer y garantizar el ejercicio del derecho de los NNA a su identidad de género y al reconocimiento de su identidad, respectivamente, como forma de alinearse con el desarrollo de los estándares del derecho internacional, al tiempo que abordar, de ese modo, varias de las dimensiones del reconocimiento de NNA como sujetos de derecho y favorecer el término de situaciones graves de afectación de derechos que hemos tristemente conocido ${ }^{6}$. Esta inclusión en ambos proyectos de ley, por la que abogamos, serviría además para abordar los dos enfoques con que este tema debe ser mirado: el reconocimiento de la identidad y los mecanismos de tutela frente a las vulneraciones.

Para sostener lo anterior, comenzaremos (2) delineando los estándares, principios y consideraciones centrales relativos al derecho constitucional a la identidad de género. Enseguida, (3) abordamos la situación específica de los NNA, según se ha desarrollado en el derecho internacional y constitucional. Estos avances, que descansan en el reconocimiento de la identidad de género desde un enfoque de derechos, deben guiar la labor legislativa y orientarla al

En el caso de que se haga lugar a la solicitud presentada por una persona menor de 18 años o a favor de ella en conformidad con las disposiciones de la presente ley, de forma excepcional, el o la solicitante podrá por una sola vez solicitar personalmente una nueva rectificación, hasta un año contado desde que haya alcanzado la mayoría de edad, sujetándose a las disposiciones de la presente ley. Excepcionalmente, en casos calificados y fundados en el interés superior del niño, el menor de 18 años podrá solicitar una nueva rectificación".

${ }^{6}$ La Encuesta Nacional de Clima Escolar en Chile 2016, realizada por la Fundación Todo Mejora sobre la experiencia de niños, niñas y adolescentes lesbianas, gays, bisexuales y trans en establecimientos educacionales, relacionadas con su orientación sexual e identidad de género, tuvo como objetivo conocer las experiencias de bullying y acoso escolar de niños, niñas y adolescentes lesbianas, gays, bisexuales y trans durante el año escolar 2015 y evidenció una tremenda y dura realidad. Esta incluyó si escucharon comentarios malintencionados, si se sintieron seguros/as, si fueron acosados/as y si se sintieron cómodos/as o no en sus centros de estudio. También se les preguntó acerca de sus experiencias académicas; sus actitudes hacia la escuela, la participación en la misma y la disponibilidad de recursos de apoyo escolar. La muestra final estuvo compuesta por un total de 424 estudiantes entre los 13 y 20 años. Los estudiantes provinieron de las 15 regiones de Chile. Más de la mitad se identificaron como mujeres (52,8 \%), casi una cuarta parte como hombres $(20,9 \%$ ) y un $8,5 \%$ como trans. Adicionalmente, 3 de cada 4 participantes $(74,2 \%)$ se identificaron como gay o lesbiana. Como principales resultados en relación con nuestro tema se puede indicar que en materia de seguridad escolar un 29,7 $\%$ se sintió inseguro/a debido a la forma en que expresan su género; en cuanto a la victimización, un $59,9 \%$ fue acosado verbalmente debido a su expresión de género; un 28,6 \% fue atacado físicamente en la escuela debido a su expresión de género; un 31,4 \% fue acosado sexualmente, y un 31,1 \% fue acosado a través de las redes sociales (cyberbullying). 
reconocimiento de los derechos de los NNA (incluidos los proyectos que, desde ya, buscan extender el reconocimiento y protección del derecho a la identidad de género a NNA menores de 14 años) ${ }^{7}$. Las dos secciones siguientes se dedican a observar algunos desarrollos recientes que han tenido lugar a nivel doméstico. Así, (4) analizamos alguna jurisprudencia disponible en materia de reconocimiento a la identidad de género, a propósito de la que distinguimos los enfoques patologizantes -que pugnan con los estándares de un derecho respetuoso de la igualdad y autonomía de las personas- de los enfoques de derecho-que respetan la igual autonomía y dignidad de las personas, incluidos NNA-. En la última sección (5) revisamos, brevemente, algunas políticas públicas vigentes que han intentado ir avanzando en el reconocimiento del derecho a la identidad.

\section{Derecho a la identidad de género}

Esta sección, como se ha indicado, avanza algunas cuestiones conceptuales relativas al derecho a la identidad y, en particular, al derecho a la identidad de género. Como se anuncia en el título que inmediatamente inaugura esta sección, (2.1) estas cuestiones conceptuales se abordan desde un enfoque de derechos. Esto es, a partir del reconocimiento de la capacidad protegida jurídicamente que asiste a las personas de poder exigir al Estado un cúmulo de obligaciones que permitan el respeto, protección y promoción de su identidad-incluida la de género-.

\subsection{El derecho a la identidad}

El derecho a la identidad tiene una directa relación con las vulneraciones que sufren muchas personas que se reconocen a sí mismas o son percibidas por otros como parte de alguna determinada categoría social expuesta a mayor vulnerabilidad: migrante, apátrida, refugiado, discapacitado, indígena, gay, lesbiana, trans, bisexual o intersex y, por cierto, niños, niñas y adolescentes. En efecto, muchas veces las personas son "castigadas" por lo que ellos consideran su identidad, castigos que toman la forma de discriminación (exclusiones, distinciones o restricciones en el ejercicio de derechos) o de diversas manifestaciones de violencia (física, sicológica, verbal o, incluso, institucional), lo cual se agrava en el caso de los niños, niñas y adolescentes, quienes, como recuerda el Preámbulo de la Convención de Derechos del Niño (CDN), por su especial condición de vulnerabilidad, necesitan protección y cuidados especiales, no

7 Boletín № 12.140-17. 
obstante son, a un tiempo, titulares de los mismos derechos que los adultos, con las precisiones que corresponden a su desarrollo y crecimiento ${ }^{8}$.

Para comprender el contenido del derecho a la identidad es necesario entender previamente la misma idea de identidad. Con relación a ella, afirma un autor $^{9}$, se puede señalar que la identidad está compuesta por dos dimensiones: una de ellas es la constitución física de la persona y la otra, la constitución sicológica-intelectual. En sentido similar, se ha dicho que, dado que la identidad es una construcción permanente, que incorpora la trayectoria de la persona y sentido otorgado por el sujeto a su propia experiencia, no puede ser compartida. Cada actor construye su propia identidad, aunque pueda compartir historias, entornos y experiencias con otros miembros de los colectivos a los cuales pertenece, existiendo entonces tantas identidades como sujetos. A lo anterior podemos agregar que la identidad es un concepto dinámico, que tiene que ver con el ser mismo de cada quien, como cada quien se ve y espera ser visto y reconocido por la sociedad, incluyendo todos los aspectos que forman la personalidad individual, sean estos estáticos o cambiantes, y teniendo presente las interacciones sociales en que a cada individuo le toca participar.

Su conexión con la dignidad personal, fundamento de los derechos, es innegable. La identidad evoca los conceptos que le son más propios-unicidad, desarrollo individual y estatus "o condición de ser reconocido por otros seres humanos"10 prácticamente confundida con la identidad-poder "[l]levar a cabo, cada cual en su vida, un proyecto con impronta propia [lo que equivale a poder] realizarse como persona"11. La dignidad permite tal realización ${ }^{12}$.

Ahora bien, para ir dando contenido al derecho a la identidad, compartimos una cita del trabajo de Fernández. Desde una postura que concibe al ser humano como un ser que no es cerrado o acabado, como las cosas, y que es libre, entiende como identidad personal:

el conjunto de atributos y características que permiten individualizar a la persona en sociedad. Identidad personal es todo aquello que hace que cada cual sea 'uno mismo' y no 'otro'. Este plexo de características

${ }^{8}$ Gauché (2011).

${ }^{9}$ Nogueira (2010), p. 298.

10 Aldunate (2008), pp. 96-99.

11 Cea (2012), p. 43.

${ }^{12}$ Esta línea argumental siguió, por ejemplo, recientemente, la Excma. Corte Suprema. En efecto, sostuvo que el derecho a la identidad de género se encontraba recogido, además de en el derecho a la igualdad, en la dignidad "inherente a toda persona...". Corte Suprema, rol № 38238-16, de 19 de diciembre de 2017 , cons. $4^{\circ}$ y $5^{\circ}$. 
de la personalidad de 'cada cual' se proyecta hacia el mundo exterior, se fenomenaliza, y permite a los demás conocer a la persona (...) en lo que ella es en cuanto específico ser humano. La identidad, el ser yo mismo y no otro, se despliega en el tiempo. Se forja en el pasado, desde el instante mismo de la concepción, donde se hallan sus raíces y sus condicionamientos, pero, traspasando el presente existencial, se proyecta al futuro. La identidad es fluida, como el ser mismo. No es algo acabado y finito, sino que ella se crea en el transcurso del tiempo, con el tiempo (...). Los atributos y características que, en su totalidad, definen objetivamente la personalidad que se exterioriza, pueden tener la calidad de elementos estáticos, invariables, salvo excepciones, o dinámicos, fluidos, en proceso de cambio y de enriquecimiento. Los estáticos son los primeros elementos personales que se hacen visibles en el mundo exterior (...). Entre éstos cabe señalar a los signos distintivos, como podrían ser el nombre, el seudónimo, la imagen y otras características físicas que diferencian a una determinada persona de las demás (...). La identidad que hemos dado en llamar dinámica, se configura por lo que constituye el patrimonio ideológico-cultural de la personalidad. Es la suma de los pensamientos, opiniones, creencias, actitudes, comportamientos de cada persona que se explayan en el mundo de la intersubjetividad (...). Es todo aquello que define la personalidad proyectada hacia el exterior ${ }^{13}$.

¿Por qué es importante el reconocimiento del derecho a la identidad y su protección? En parte por las razones que venimos acá repasando. En primer lugar, porque la identidad implica el reconocimiento de la persona con su propia individualidad, de sus atributos y el aseguramiento de las condiciones que permitan el desarrollo de la misma resguardando de mejor manera las posibles vulneraciones de derechos. La identidad es, en este sentido, la marca de nuestros propios desarrollos y la carta de presentación de nuestra propia singularidad; una marca que rechaza la consideración de la persona como una unidad estadística más. La identidad personal es, finalmente, un complejo entramado de experiencias pasadas, acciones y decisiones previas, y otras no elegidas, que nos permiten decir "este soy yo, no puedo ser otro" ${ }^{14}$. Ese entramado de factores nos da forma y significado, y por ello son, sobre todo, "determinantes de nuestra individualidad"15.

13 Fernández (1992), pp. 113-114.

14 RAZ (2004), pp. 32-3.

15 RAZ (2004), p. 34. 
Por supuesto que el reconocimiento de la identidad no se agota en su dimensión puramente individual, sino que posee, además, una cara colectiva (pública) de crucial importancia. Así, el reconocimiento y protección de la identidad personal es de especial importancia en el contexto de sociedades plurales cuyas bases constitucionales, como la chilena, no se erigen sobre una determinada concepción comprensiva del bien, sino que, todo lo contrario, se construyen sobre la base de un pluralismo político que acepta, reconoce y protege las más diversas formas de vida ${ }^{16}$. Una comunidad política que hace lo contrario, esto es, una comunidad política que excluye a parte de sus miembros, que no les permite concurrir al espacio público provistos de sus propias experiencias y vivencias más íntimas; una comunidad que, a final de cuentas, distribuye derechos y responsabilidades solo permitiendo la aparición de algunas voces o de todas las voces, pero a condición que escondan o coloquen entre paréntesis aquello que las constituye como seres individuales y libres, trata con desigual consideración y respeto a sus ciudadanos y ciudadanas. Una comunidad tal, como venimos diciendo, no solo humilla y menosprecia a quienes representa en falsa luz ${ }^{17}$, sino que, al mismo tiempo, corre el riesgo de erigir sus propias bases sobre la voluntad arbitrariamente seleccionada de quienes aparecen como ciudadanos y ciudadanas plenamente reconocidos y fielmente representados, frente a otros y otras que, en cambio, o no son admitidos o son admitidos a medias.

De allí que el derecho, y en especial el derecho internacional de los derechos humanos, haya puesto especial énfasis en el reconocimiento de la identidad personal y su protección. Porque entiende que en ese reconocimiento se juega parte importante del desarrollo autónomo de la persona -no obstante, en diálogo con los demás ${ }^{18}-$. No se equivocaba el Tribunal Constitucional, entonces, cuando afirmaba -aunque lo hacía solo para enfatizar los aspectos de inscripción, derecho al nombre y acceso a conocer a sus padres- que "el reconocimiento del derecho a la identidad personal -en cuanto emanación de

\footnotetext{
${ }^{16}$ En el contexto de comunidades diversas, donde el pluralismo se evalúa como algo positivo, las políticas sociales de reconocimiento en la esfera pública -esto es, en el entramado de las relaciones discursivas y de otro orden que configuran el campo común que orienta la comunidad política- nos Ilevan a buscar el establecimiento de un universo diferenciado o -en palabras de Fraser- de un mundo amigable a la diferencia [FrASER (1999), p. 25]. En ese contexto, la asimilación a la cultura o patrones sociales de la mayoría ya no es más la meta del desarrollo de la personalidad, sino, muchas veces, la condición misma desde la que arranca la opresión [Young (1990), pp. 48-63].

17 Honneth (1997), pp. 160-161.

${ }^{18}$ Marshall (2009), pp. 91-93.
} 
la dignidad humana-implica la posibilidad de que toda persona pueda ser ella misma y no otra ..."19.

Algo similar ocurre con las regulaciones en materia de igualdad y no discriminación. Allí, las denominadas categorías sospechosas -ese cúmulo de características que las cláusulas de no discriminación suelen enumerar, aunque no de manera taxativa, como categorías conforme a las que no es posible diferenciar sin justificación objetiva y razonable- son vistas como bases sobre las que corrientemente se realizan decisiones basadas en estereotipos que, de este modo, prescinden del mérito "y se toman sobre la base de características personales que son inmutables o alterables [piénsese en la identidad de género] únicamente a un costo inaceptable para la identidad personal" ${ }^{\prime 20}$. Y ello es evidente pues demandan la propia negación o, cuando tomadas desde afuera, el desconocimiento de nuestra propia individualidad.

\subsection{Identidad de género desde un enfoque de derechos}

La identidad de género, qué duda cabe, es una manifestación específica de este derecho a la identidad general. Para apreciar su alcance y relación con lo dicho hasta acá, conviene comenzar distinguiendo la identidad de género del sexo. El "sexo" corresponde al conjunto de características biológicas, principal, aunque no exclusivamente, anatómicas, "que definen a los seres humanos como femenino y masculino"21. Dicha determinación se realiza al momento del nacimiento a través de la inspección visual de los genitales de los recién nacidos, inspección que, colocando especial énfasis en la manifestación externa de la anatomía, prescinde de otras pruebas, como las genéticas o cromosómicas ${ }^{22}$.

La "identidad de género", en cambio -y a diferencia de la anatómica, que es asignada luego de la inspección-, es una identidad adquirida, aprendida durante el tiempo y que reposa sobre una serie de variables que, dependiendo de específicos contextos culturales, cambian ${ }^{23}$. De allí que suela definírsela a

\footnotetext{
19 Tribunal Constitucional de Chile, STC rol No 1340-2009, de 29 de septiembre 2009, cons. $10^{\circ}$. En sentido similar, Tribunal Constitucional de Chile, STC rol № 834-2007, de 13 de mayo de 2008, cons. $15^{\circ}$. ${ }^{20}$ Corbiere v. Canada (Minister of Indian and Northern Affairs), [1999] 2 SCR 203, 1999 CanLII 687 (SCC).

${ }^{21}$ COUPet (2015), p. 187.

22 COUPET (2015), p. 187. Este tipo de evaluaciones sociales que ofrecen ciertas categorías como naturales, además, podrían tener un impacto decisivo en la determinación de otras estructuras que, como la de la familia, también se leen a partir de un determinado cúmulo de evaluaciones sociales y culturales. MCCLAIN (2013), p. 41.

${ }^{23}$ Coupet (2015), p. 187.
} 
partir de la vivencia interna e individual que las personas experimentan, vivencia que puede corresponder o no con la del sexo (asignado).

Desde luego que, de lo anterior, no se sigue que estas expresiones anatómicas no sean, ellas mismas, objeto de una determinada lectura y evaluación social y cultural. En efecto, una de las razones por las que se privilegia el examen anatómico descansa en que el sexo opera como una categoría de clasificación dependiendo de la supuesta capacidad reproductiva de uno y otro -o la complementariedad natural, desde alguna mirada confesional- ${ }^{24}$.

Es posible, por lo tanto, que exista una discordancia entre el sexo asignado, cuando no impuesto, al nacer y nuestra identidad de género. Hay ocasiones en que esa discordancia es parte de una incomodidad que acompaña a las personas. Esa discordancia como incomodidad, si se nos permite denominarla de este modo, entre el sexo asignado al nacer y la identidad de género, antiguamente entendida como un desorden de identidad de género, es hoy denominada por alguna literatura disforia de género y no es considerada en sí misma como un desorden mental -como tampoco lo es, desde luego, la identidad de género-. En efecto, el Manual Diagnóstico y Estadístico de Trastornos Mentales (de la American Psychiatric Association) afirma que existió la necesidad de incluir el término "género" para dar cuenta de la experiencia de vida de muchas personas cuya identificación masculina o femenina - u otra- "no podía ser asociada o predeterminada a partir de los indicadores biológicos" 25-26.

Hay otras ocasiones, sin embargo, en las que esa discordancia está lejos de ser reflejo de una incomodidad, sino que, en cambio de ello, manifestación del derecho de las personas a la autodeterminación de su identidad, de conformidad -nos excusarán la insistencia- a sus propias vivencias y experiencias. Quizá la definición de identidad de género contenida en la Ley Antidiscriminación de la provincia de Queensland, Australia (1991), nos permita identificar mejor la diferencia entre la discordancia como incomodidad y el ejercicio del derecho a la autodeterminación y la identidad. Dispone dicha ley que la identidad de género,

en relación a una persona, significa que esa persona

\footnotetext{
${ }^{24}$ Sobre esto volveremos al finalizar la sección 4.1 sobre jurisprudencia nacional.

25 APA (2013), p. 451.

${ }^{26}$ De esto no se sigue, desde luego, que las personas que viven procesos de disforia, en parte por el espacio cultural y las presiones en que se mueven, no experimenten otras formas de estrés emocional y psíquico que merezca atención. Por ejemplo, el mismo manual advierte que muchos de esos episodios de aflicción que afectan a personas transgénero -y que no las afectan a todas por igual- bien pueden deberse a la falta de "intervenciones físicas a través de hormonas o intervenciones quirúrgicas" [APA (2013), p. 451].
} 
(a) se identifica, o se ha identificado, como un miembro de sexo opuesto al vivir o buscar vivir como un miembro de ese sexo; o

(b) es una persona de sexo indeterminado y busca vivir como miembro de un sexo en particular.

¿Tienen derecho las personas a ser protegidas en esa (auto) comprensión? En el derecho internacional de los derechos humanos, esta pregunta ha encontrado eco en los denominados "Principios de Yogyakarta", relativos a la aplicación del derecho internacional de los derechos humanos con relación a la orientación sexual y derecho a la identidad. En ellos, se avanza en una conceptualización más acabada para entender la identidad de género como la vivencia interna e individual del género tal como cada persona la siente profundamente, la cual podría corresponder o no con el sexo asignado al momento del nacimiento, incluyendo la vivencia personal del cuerpo (que podría involucrar la modificación de la apariencia o la función corporal a través de medios médicos, quirúrgicos o de otra índole, siempre que la misma sea libremente escogida) y otras expresiones de género, incluyendo la vestimenta, el modo de hablar y los modales.

Además, en la revisión de este instrumento, adoptada el 10 de noviembre de 2017 en Ginebra por un grupo de expertos, se considera como el principio 31 el derecho al reconocimiento legal y a obtener documentos de identidad, incluidos certificado de nacimiento independiente de la identidad de género, así como a cambiar dicha información.

Lo propio puede decirse de diversas decisiones de tribunales internacionales que han reconocido paulatinamente el derecho a la identidad de género, basados en los tratados internacionales de derechos humanos. Así, la Corte Europea de Derechos Humanos sostuvo en Van Kück v. Germany que la "identidad de género, el nombre y la orientación sexual, así como la vida sexual de las personas, caben dentro de la esfera de personalidad"27 protegida por el Convenio Europeo de Derechos Humanos y que incluye "el derecho al desarrollo personal, y el derecho a establecer y desarrollar relaciones con otros seres humanos" 28 . La Corte Interamericana de Derechos Humanos, por su parte, señaló que deja establecido que la orientación sexual y la identidad de género de las personas son categorías protegidas por la Convención. Por ello está proscrita por la Convención cualquier norma, acto o práctica discriminatoria basada en la orientación sexual de la persona. En consecuencia, ninguna norma, decisión o

${ }^{27}$ Corte Europea de Derechos Humanos, Application N №35968/97, de 12 de septiembre de 2003, párr. 69.

${ }^{28}$ Corte Europea de Derechos Humanos, Application № 35968/97, de 12 de septiembre de 2003, párr. 69. 
práctica de derecho interno, sea por parte de autoridades estatales o por particulares, pueden disminuir o restringir, de modo alguno, los derechos de una persona a partir de su orientación sexual29.

Más recientemente, y todavía a nivel regional, la Corte Interamericana de Derechos Humanos ha publicado la Opinión Consultiva 24/17, sobre Identidad de Género, e Igualdad y no Discriminación a Parejas del Mismo Sexo ${ }^{30}$. Allí, la corte, reconociendo la igual dignidad de las personas, que se encuentra dijo- en la base de la autonomía de todas ellas, sostuvo que la Convención Americana de Derechos Humanos protege su derecho a "desarrollar su propia personalidad, aspiraciones, determinar su identidad y definir sus relaciones personales" ${ }^{\prime \prime 1}$. Este derecho incluye la facultad de las personas para escoger libremente las opciones que le den "sentido a su existencia" ${ }^{32}$ y, por lo tanto, a la protección de su identidad:

el conjunto de atributos y características que permiten la individualización de la persona en sociedad y que, en tal sentido, comprende varios derechos según el sujeto de derechos de que se trate y las circunstancias del $\mathrm{caso}^{33}$.

Citando el caso Atala, antes referido, avanzó a afirmar que la identidad de género y sexual se encuentra ligada a la libertad de las personas para autodeterminarse y, como había dicho, poder conferir sentido a sus vidas. En consonancia con lo que se ha venido diciendo acá, la identidad de género importa el resguardo de esa esfera de autodeterminación. De allí que, como ha ocurrido en otros instrumentos del derecho internacional de los derechos humanos, la entienda como la vivencia interna e individual del género tal como cada persona la siente, la cual podría corresponder o no con el sexo asignado al momento del nacimiento. Lo anterior, conlleva también a la vivencia personal del cuerpo y otras expresiones de género, como lo son la vestimenta, el modo de hablar y los modales (...). En esa línea, para esta Corte, el reconocimiento de la identidad de género se encuentra ligada necesariamente con la idea según la cual el sexo y el género deben ser percibidos como parte de una construcción identitaria

\footnotetext{
${ }^{29}$ Corte IDH, Serie C No 239, de 24 de febrero de 2012, párr. 91.

30 Corte IDH, OC-24/17, de 24 de noviembre de 2017.

31 Corte IDH, OC-24/17, de 24 de noviembre de 2017, párr. 87.

32 Corte IDH, OC-24/17, de 24 de noviembre de 2017, párr. 88.

33 Corte IDH, OC-24/17, de 24 de noviembre de 2017, párr. 90.
} 
que es resultado de la decisión libre y autónoma de cada persona, sin que deba estar sujeta a su genitalidad ${ }^{34}$.

La conexión, entonces, entre identidad de género y derecho a la identidad es estrecha y -en palabras de la corte- constitutiva ${ }^{35}$.

\subsection{Respecto al ejercicio de derechos}

Al enfoque de derechos, sin embargo, se le opone una visión -más extendida, lamentablemente- que mira las transiciones de género (incluso para reconocerlas) como manifestación de alguna patología. Este enfoque patologizante se construye, principalmente, con base en dos razones. Primero, en la preferencia normativamente abrazada de que el sexo representa una categoría natural y que la identidad de género que se aparta de la correspondencia que esa misma preferencia considera como natural (como en general ocurre con la identidad heterosexual en cuanto a la orientación sexual) es un problema médico que merece una suerte de compasión jurídica. Segundo, a una falta de observación o mala comprensión del ejercicio de derechos de autonomía constitucional.

\section{A. Sexo e identidad como categorías naturales}

El acercamiento patologizante a la transexualidad, dominante en las decisiones sobre cambio de nombre -incluidas algunas de las que acogen las solicitudes, como veremos más adelante-, muestra que categorías como el sexo se asumen como naturales e inamovibles -no obstante ella misma es fruto de ideologías y patrones culturales prevalentes desde tiempos ancestrales-. Ello se debe en parte importante a lo que Franke ha denominado uno de los principales errores en los que ha incurrido la legislación antidiscriminación: el de asumir que el sexo se construye sobre la base de consideraciones biológicas, lo que le confiere un lugar preferente al género ${ }^{36}$, y en consecuencia "más real".

En este caso concreto, la ideología se expresa en la cisnormatividad: una suerte de esencialismo anatómico que atribuye a las personas la identidad de género que de conformidad a las pautas prevalentes se condice con su identificación

\footnotetext{
34 Corte IDH, OC-24/17, de 24 de noviembre de 2017, párr. 94.

35 La corte lo dice así: "la identidad de género es un elemento constitutivo y constituyente de la identidad de las personas, en consecuencia, su reconocimiento por parte del Estado resulta de vital importancia para garantizar el pleno goce de los derechos humanos de las personas transgénero, incluyendo la protección contra la violencia, tortura, malos tratos, derecho a la salud, a la educación, empleo, vivienda, acceso a la seguridad social, así como el derecho a la libertad de expresión, y de asociación". Corte IDH, OC-24/17, de 24 de noviembre de 2017, párr. 98.

36 Franke (1995).
} 
genital ${ }^{37}$, y cuyas ramificaciones alcanzan a la conceptualización misma de la familia, el matrimonio y la parentalidad ${ }^{38}$. La patologización de la identidad de género se verifica porque el cambio de nombre tiene lugar solo allí donde está médicamente probada la discordancia o, peor aún (peor en el entendido de que solo así pueden acceder al reconocimiento de su identidad), solo allí donde la persona trans se ha sometido a una cirugía que la haga compatible con la estructura binaria del sexo y la expresión que se asume como la correcta respecto de cada cuerpo.

Es cierto, como ha indicado Fernando Muñoz, que a estos efectos suele producirse una suerte de comunión entre las epistemologías jurídica y médi$\mathrm{ca}^{39}$. Sin embargo, esa comunión viene de la mano con la falta de atención adecuada a los derechos fundamentales que esas exigencias de prueba médica o adecuación genital dejan de lado -cosa que, en todo caso, Muñoz también advierte- ${ }^{40}$.

Sea que esa cisnormatividad sea leída implícitamente en las regulaciones legales, arrojada explícitamente en la cara de aquellos y aquellas cuyas demandas son rechazadas o asumida de cara a una transnormatividad culposa ${ }^{41}$, la jurisprudencia vigente -casi en su mayoría- muestra que solo es posible escapar de ella acusando algún desorden certificado médicamente ${ }^{42}$. Este acercamiento es inaceptable en una comunidad democrática que reconoce derechos fundamentales a sus ciudadanos y que, junto a ello, les asegura espacios protegidos constitucionalmente para el ejercicio de la autonomía.

\footnotetext{
37 MUÑOZ (2016), p. 168.

${ }^{38}$ MCCLAIN (2013), pp. 43-47.

39 MuÑoz (2015), pp. 1018-1019.

40 MuÑoz (2015), p. 1019. Nótese, por ejemplo, la forma en que la Corte Constitucional de Colombia se acercó a la definición del derecho a la identidad de género:

"El derecho a la identidad es materialización del libre desarrollo de la personalidad, pues en estrecha relación con la autonomía, la persona se identifica o autodetermina, se autoposee, se autogobierna, es dueña de sus actos y entorno con el cual establece su plan de vida y su individualización como persona singular, elementos esenciales para la construcción de su identidad de género". Corte Constitucional de Colombia, T-476/14, de 9 de julio de 2014.
}

${ }^{41}$ MuÑoz (2016), pp. 176-178.

${ }^{42}$ Algo similar pudo advertirse en el proyecto de ley que Reconoce y da Protección al Derecho a la Identidad de Género (Boletín Nº 8924-07). En efecto, allí, en algún momento, se exigió fundar la solicitud de rectificación de la partida de sexo, presentando "una evaluación médica realizada por un experto calificado en la materia, con el objeto de determinar que él o la solicitante cuenta con las condiciones psicológicas y psiquiátricas necesarias para formular la solicitud a que se refiere la presente ley" (art. $\left.4^{\circ}\right)$. 


\section{B. Derechos constitucionales de autonomía}

El enfoque patologizante de la identidad de género, en efecto, va de la mano con un acercamiento descuidado al ejercicio de derechos constitucionales de autonomía (o de la personalidad). En efecto, los derechos de autonomía representan una protección jurídicamente demandable de esferas de autodeterminación que pueden tener (como las expresiones de género) como no tener (como la identidad de género) una manifestación fenomenológica. Antes bien, se trata de derechos que buscan "habilitar a las personas a tomar control de sus vidas" ${ }^{\prime 3}$. Por eso es que se ha dicho, acertadamente, que, respecto de los derechos de autonomía como autodeterminación, le está vedado al Estado "que intervenga... basándose en que la decisión es adoptada por el sujeto es inaceptable, moralmente autodegradante o contraria a determinados ideales de virtud, excelencia o de salvación" ${ }^{\prime 4}$.

Ante la incomprensión de lo que los derechos de autonomía protegen, los tribunales avanzan a indagar en el fuero interno de las personas a efectos de determinar si acaso se trata de una voluntad sinceramente expuesta. Algo así como si los tribunales estuvieran escrutando si acaso las personas que reclaman protección de sus derechos a la autodeterminación personal están fidedignamente, esto es, apoyadas por un diagnóstico médico, autodeterminándose. Nótese que en el caso del acercamiento patologizante al derecho a la identidad de género, ni siquiera es que los tribunales estén preocupados de cuidar que las decisiones de las personas sean libres -lo que es relevante respecto de NNA-, sino que, derechamente (y por eso es patologizante), pretenden definir si ese reclamo se erige sobre una decisión realmente sentida, médica y, en consecuencia, inescapable. En otras palabras, este acercamiento patologizante importa una forma de coerción que, a diferencia de la asimilación forzada -esa que antes exigía adecuación quirúrgica-, descansa, ahora, en un diagnóstico ${ }^{45}$.

Aceptar este acercamiento a los derechos de autonomía termina por privarlos de todo valor. Piénsese, por ejemplo, si se trasladara este mismo enfoque al ejercicio de otros derechos de autonomía, como la libertad de conciencia y culto. ¿Posee la sola creencia, desprovista de ejercicio, de una concreción en la realidad que le permita al tribunal tener por acreditada, por caso, la existencia de la fe de una persona? Desde luego que no. ¿Está esa creencia, sin embargo, protegida constitucionalmente? Por supuesto que sí. Sobre esto no hay dudas. La libertad de conciencia, afirma Vivanco, "implica la formación

43 MÖller (2009), p. 158.

44 Gómez (2005), p. 319.

45 Yoshino (2007), pp. 92-93. 
personal de valores y pertenece a la intimidad de la persona..." ${ }^{\prime 4}$. ¿Qué papel cabe al Estado? "[S]ólo le corresponde proteger la conciencia y asegurarse que sea libre..." ${ }^{\prime 7}$. Adviértase lo humillante que sería para el reconocimiento y ejercicio de esa libertad (al punto de desnaturalizarla) exigir a quienes reclaman protección constitucional la necesidad de tener que acreditar, médicamente, que su afirmación de adherir a un determinado culto es "inescapable"48. Imagínese el impacto que tendría un enfoque igualmente patologizante para el ejercicio de derechos de autodeterminación, como la libertad de culto, si las personas que se acercaran a tribunales a solicitar resguardo constitucional fueran obligadas a exhibir prueba psiquiátrica de su verdadera adhesión a una determinada religión ${ }^{49}$.

\footnotetext{
${ }^{46}$ Vivanco (2006), p. 398.

47 Vivanco (2006), p. 398.

${ }^{48}$ Nótese, a estos efectos, la forma en que se ha identificado la misma libertad de conciencia:

"El primer nivel es el que nos permite reconocer en nuestro fuero interno que las cosas "son", que "existen", que están allí. También, se refiere a identificarnos a nosotros mismos, y a lo que sucede en nuestro interior, como algo que existe, que "es". Este primer nivel no es, por tanto, la mera percepción por los sentidos de que algo ocurre, sino que se refiere al procesamiento de la información que se recibe por los sentidos, a la imagen que se forma en nuestro intelecto acerca de aquello que ya hemos captado. De allí que cuando alguien conoce algo, se dice que "ha tomado conciencia" de que existe. A este primer nivel, se le denomina "conciencia psicológica o sensible", o como dice Hegel "la certeza inmediata" o "la certeza de lo inmediato"". TÓRTORA (2012), p. 91.
}

49 Desde luego que parte importante del acercamiento patologizante se explica por la falta de una adecuación legislativa y procedimental que reconozca el derecho a la identidad de género. En un contexto tal, se recurre a la labor interpretativa jurisdiccional, la que, de alguna manera, inevitablemente echa mano a la prueba en tanto mecanismo por medio del que las partes acreditan sus pretensiones ante tribunales y, sobre todo, los jueces y juezas se imponen de los hechos. En efecto, podría decirse que la misma Ley № 17.344 establece la necesidad de acreditar ciertos supuestos en las hipótesis más comunes en el asunto bajo estudio, reguladas en el artículo $1^{\circ}$, letras a) y b). En el caso de la letra b) -haber sido conocido "durante más de cinco años, por motivos plausibles, con nombres o apellidos, o ambos, diferentes de los propios"- es posible pensar en mecanismos probatorios que escapan del acercamiento patologizante (como testigos que puedan declarar que tal persona ha sido conocida por su nombre social, por ejemplo). Eso es más complejo en el caso de la hipótesis de la letra a), que exige mostrar un menoscabo moral o material.

Sin embargo, ¿es efectivo que el menoscabo moral o material pueda solo acreditarse a través de pruebas de perfil médico? Sostenemos que el enfoque es patologizante, justamente, porque no descansa únicamente en esa falta de adecuación legislativa y procedimental, sino en algo más -para lo que vale todo lo dicho hasta acá-. En efecto, no debe dejar de anotarse que el procedimiento de cambio de nombre es una de esas gestiones judiciales que el Código de Procedimiento Civil (CPC) denomina como no contenciosas (Libro IV, Título I). Una gestión en la que no hay partes, sino interesados e interesadas, y en la que, incluso cuando los tribunales deban "proceder... con conocimiento de causa", no es necesario que lo hagan sujetándose a las "solemnidades ordinarias de las pruebas judiciales", pudiendo -esto es lo importante- recurrirse a "informaciones sumarias" (artículo 818, CPC). 
La Ley que Reconoce y da Protección al Derecho a la Identidad de Género, promulgada el día 28 de noviembre de 2018, si bien no hace descansar la solicitud de rectificación de sexo y nombre registral en un diagnóstico, tratándose de personas adultas demanda que esa solicitud vaya acompañada de la deposición de dos testigos hábiles (art. 11, inc. $2^{\circ}$ ). ¿Cuál es la función de esos dos testigos? Dar fe de que quien solicita el cambio registral "conoce todos los efectos jurídicos que implica el acogimiento de la solicitud", una forma de paternalismo referida al ejercicio de derechos constitucionales de autonomía inaceptable.

De lo anterior no se sigue que, en otros contextos, no deba exponerse prueba de sinceridad de las creencias. Pero ello se demanda en contextos en que las personas recurren a su esfera de la personalidad autodeterminada para reclamar un trato excepcional (como las exenciones a que da lugar la objeción de conciencia), exigiendo ser puestas al margen del cumplimiento de obligaciones generales ${ }^{50}$. No, en cambio, para avanzar a su autodeterminación. Del mismo modo, los derechos de autonomía protegen espacios de autodeterminación y no facultan a su titular para infligir daños a terceras personas. Esto es bastante evidente, pero no conviene dejar de mencionarlo. Los derechos de autodeterminación de la personalidad, como la identidad, importan la autodefinición y no la afectación de terceras personas. De allí que, como lo indica Gómez, se trata de derechos que confieren a las personas "un espacio de autodeterminación individual para adoptar decisiones sobre cuestiones que incumben al que las adopta y que no dañan a terceros ${ }^{\prime \prime 5}$.

De otra parte, es también posible que algunas relaciones jurídicas puedan verse alteradas por la autodeterminación. Pero allí, cuando están en juego esas eventuales afectaciones, es precisamente cuando se espera la intervención de los tribunales. En cualquier caso, ninguna de esas intervenciones se hace a efectos de exigir tener por acreditada (menos para evaluar) la propia determinación y vivencia, sino que, en cambio, para cotejar esa determinación con los otros intereses de terceras partes que entran en consideración y que, dicho sea de paso, "no pueden restringir ilegítimamente derechos fundamentales del ser humano" 52 .

\footnotetext{
50 Greenawalt (2006), p. 109.

51 Gómez (2005), p. 319.

52 EsPejo y LatHrop (2015), pp. 396-403. En general, es difícil pensar en casos en que el solo ejercicio y protección de la autodeterminación personal pueda lesionar derechos de terceras personas. Ello podría ocurrir, en cambio, cuando las personas, amparadas en una eventual protección de su autodeterminación, demandan afectar derechos de terceras personas como una forma de satisfacción de sus intereses constitucionalmente protegidos. Nejaime y Siegel (2015).
} 


\section{Identidad de género de los NNA}

¿Se extiende el reconocimiento del derecho a la identidad a los NNA? Los NNA son personas y, por lo tanto, titulares de derechos constitucionales. Entre ellos, del derecho a la identidad. Este derecho se encuentra expresamente reconocido en el art. 8.1 de la Convención sobre los Derechos del Niño (CDN), en los términos siguientes:

Los Estados Partes se comprometen a respetar el derecho del niño a preservar su identidad, incluidos la nacionalidad, el nombre y las relaciones familiares de conformidad con la ley sin injerencias ilícitas.

Por su parte, el art. $7^{\circ}$ señala que el niño será inscrito inmediatamente después de su nacimiento y tendrá derecho desde que nace a un nombre, a adquirir una nacionalidad y, en la medida de lo posible, a conocer a sus padres y a ser cuidado por ellos. Esta consagración debe entenderse en directa relación y armonía con los principios rectores de la misma CDN, a saber: con el principio de no discriminación (art. $2^{\circ}$ ), que es además directriz de todo el sistema internacional de protección de derechos humanos como forma de materializar la igualdad entre las personas; con el principio y derecho a que su interés superior sea la consideración primordial en toda decisión que le concierna (art. $3^{\circ}$ ); con el principio y derecho a que pueda expresar su opinión libremente y se tengan en cuenta en las decisiones, en función de su edad y madurez (art. 12), y con el respeto que el Estado debe dar a quienes ejercen responsabilidad parental o a quienes están legalmente encargados de impartir dirección y orientación apropiadas para que el niño ejerza sus derechos, en consonancia con la evolución de sus facultades (art. $5^{\circ}$ ). Todo lo anterior es consecuencia de la consideración que atraviesa la CDN conforme a la que, en el caso de los NNA, el ejercicio de derechos supone, por las condiciones especiales en las que se encuentran, la adopción de ciertas medidas específicas con el propósito de que gocen efectivamente de tales dichos derechos y garantías ${ }^{53}$.

Antes, el Pacto Internacional de Derechos Civiles y Políticos (1966), si bien no definió ni reguló el derecho a la identidad, consagró para los NNA ciertos derechos que están directamente relacionados con la identidad, tales como el derecho a ser inscrito al nacer y el derecho a adquirir una nacionalidad ${ }^{54}$. Por

${ }^{53}$ Corte Interamericana de Derechos Humanos, Opinión Consultiva 17/2002, de 28 de agosto de 2002, Condición Jurídica y Derechos Humanos del Niño, párr. 98.

${ }^{54}$ Así, el art. 24.1 dispone:

"Todo niño tiene derecho, sin discriminación alguna por motivos de raza, color, sexo, idioma, religión, origen nacional o social, posición económica o nacimiento, a las medidas de protección que su condición de menor requiere, tanto por parte de su familia como de la sociedad y del Estado. 2. Todo 
otra parte, y luego de la adopción del CDN, la Declaración de Naciones Unidas sobre la Protección de Todas las Personas contra las Desapariciones Forzadas o Involuntarias (1992) sostuvo en su art. 20 que:

La apropiación de niños de padres víctimas de desaparición forzada o de niños nacidos durante el cautiverio de una madre víctima de una desaparición forzada, así como la falsificación o supresión de documentos que atestigüen su verdadera identidad, constituyen delitos de naturaleza sumamente grave que deberán ser castigados como tales.

Esta disposición se ve reforzada por la Convención Internacional para la protección de todas las personas contra las desapariciones forzadas (art. 25) y por la Convención Interamericana sobre Desaparición Forzada de Personas (art. 12).

¿El derecho a la identidad comprende la identidad de género? Desde luego que sí. Tal y como lo señaló la Corte Interamericana en su OC-24/17, los NNA son titulares de los mismos derechos que la convención reconoce a los adultos, entre ellos el derecho a la identidad de género ${ }^{55}$. Anotando la especial situación de vulnerabilidad en la que se encuentran los NNA, pero advirtiendo acertadamente que la misma no puede ser una razón que se esgrima para lesionar la titularidad de derechos, afirmó, de manera elocuente, que,

las consideraciones relacionadas con el derecho a la identidad de género que fueron desarrolladas supra [para adultos] también son aplicables a los niños y niñas que deseen presentar solicitudes para que se reconozca en los documentos y los registros su identidad de género auto-percibida ${ }^{56}$.

¿Cómo dar cuenta de la especial condición de vulnerabilidad de los NNA, al tiempo que se les garantiza el derecho a la identidad de género? Como en otras áreas -piénsese, por caso, lo que ocurre en materia de responsabilidad penal adolescente-, los Estados tienen a este respecto un deber calificado, más exigente, pero que en caso alguno los habilita para desconocer derechos:

Este derecho debe ser entendido conforme a las medidas de protección especial que se dispongan a nivel interno de conformidad con el artículo 19 de la Convención, las cuales deben diseñarse necesariamente en concordancia con los principios del interés superior del niño y de la niña, el de la autonomía progresiva, a ser escuchado y a que se tome en cuenta su opinión en todo procedimiento que lo afecte, de respeto al

niño será inscrito inmediatamente después de su nacimiento y deberá tener un nombre. 3. Todo niño tiene derecho a adquirir una nacionalidad".

${ }^{55}$ Corte IDH, OC-24/17, párr. 149.

${ }^{56}$ Corte IDH, OC-24/17, párr. 154. 
derecho a la vida, la supervivencia y el desarrollo, así como al principio de no discriminación ${ }^{57}$.

Por último, la corte ha sido enfática en sostener que, de aplicarse a los NNA los derechos generales que dispone la Convención, ello debe hacerse "tomando en consideración el corpus juris sobre derechos de la infancia". ¿Qué puede afirmarse a este respecto? En primer lugar, cabe advertir que el derecho a la identidad que consagra el art. 8.1 va más allá de los resguardos adecuados para poder identificar al NNA recién nacido (como la inscripción en registro del nacimiento). Ello es evidente en tanto dichos aspectos se encuentran cubiertos por los arts. $7^{\circ}, 9^{\circ}, 18$ y $21 \mathrm{CDN}$. No se trata, entonces, de una disposición redundante de esas regulaciones, ni la lista de menciones (nacionalidad, nombre y relaciones familiares) fue pensada para ser exhaustiva (Stewart 1992, 223-4 $)^{58}$. Más recientemente, la Corte Interamericana de Derechos Humanos ha detallado los alcances de la comprensión del derecho a la identidad del art. $8^{\circ} \mathrm{CDN}$, afirmando que,

el derecho... puede ser conceptualizado, en general, como el conjunto de atributos y características que permiten la individualización de la persona en sociedad y, en tal sentido, comprende varios otros derechos según el sujeto de derechos de que se trate y las circunstancias del caso ${ }^{59}$.

Este derecho, entonces, incluye el respeto a la identidad de aquellas áreas de la autocomprensión y aceptación relativas, por ejemplo, al género, pero también a otras que influyen de manera decisiva en la identidad personal de NNA, como, por ejemplo, la identidad familiar. De allí que la identidad personal-como lo ha puesto de manifiesto la Corte Interamericana de Derechos Humanos- "esté íntimamente ligada a la persona en su individualidad específica y vida privada, sustentadas ambas en una experiencia histórica y biológica, así como en la forma en que se relaciona dicho individuo con los demás..." ${ }^{60}$. Como se ha indicado,

\footnotetext{
${ }^{57}$ Corte IDH, OC-24/17, párr. 154.

${ }^{58}$ En sentido similar, Corte IDH, Serie C No 232, de 31 de agosto de 2011, párr. 112:

"En su artículo 8.1 señala que '[l]os Estados Partes se comprometen a respetar el derecho del niño a preservar su identidad, incluidos la nacionalidad, el nombre y las relaciones familiares de conformidad con la ley sin injerencias ilícitas'. De la regulación de la norma contenida en la Convención sobre Derechos del Niño se colige que la identidad es un derecho que comprende varios elementos, entre ellos, se encuentra compuesto por la nacionalidad, el nombre y las relaciones familiares, incluidos en dicho articulado a modo descriptivo mas no limitativo".

${ }^{59}$ Corte IDH, Serie C No 221, de 24 de febrero de 2011, párr. 122. No en vano, la corte ha desarrollado profusamente este derecho a propósito de la identidad indígena de los NNA, relacionando los arts. $8^{\circ}$ y 30, CDN. Véase Corte IDH, Serie C No 212, de 25 de mayo de 2010.

${ }^{60}$ Corte IDH, Serie C No 242, de 27 de abril de 2012.
} 
fuera de las menciones que efectúa el propio art. 8.1 CDN, otros aspectos de la identidad que se incluyen son la apariencia física del niño, sus habilidades, su identidad de género y su orientación sexual ${ }^{61}$.

En segundo lugar, el art. 8.1 CDN debe interpretarse en concordancia con otras disposiciones que van dotando al derecho a la identidad de un contenido dinámico; determinación de contenido en la que al NNA le cabe un papel crucial. En efecto, el art. 8.1, antes identificado, debe leerse de la mano con el reconocimiento del interés superior del niño como consideración primordial (art. 3.1) y el derecho de los NNA que estén en condiciones de formarse un juicio propio a expresar su opinión y a que esta sea debidamente tomada en cuenta (art. 12).

Tomando en cuenta estas relaciones, el Comité de Derechos del Niño de Naciones Unidas ha señalado que "Los niños no son un grupo homogéneo, por lo que debe tenerse en cuenta la diversidad al evaluar su interés superior. La identidad del niño abarca características como el sexo, la orientación sexual, el origen nacional, la religión y las creencias, la identidad cultural y la personalidad. Aunque los niños y los jóvenes comparten las necesidades universales básicas, la expresión de esas necesidades depende de una amplia gama de aspectos personales, físicos, sociales y culturales, incluida la evolución de sus facultades. El derecho del niño a preservar su identidad está garantizado por la Convención (art. $8^{\circ}$ ) y debe ser respetado y tenido en cuenta al evaluar el interés superior del niño"62.

El contenido dinámico del derecho a la identidad, anotadas las consideraciones antes expuestas, relativas al desarrollo de la personalidad y su impacto en la autonomía de las personas, no debiera sorprendernos. Jaap Doek, por ejemplo, y a propósito del contenido peculiar del art. 8.1 -que no encuentra modelo en otro instrumento del derecho internacional de los derechos humanos-, advierte que la Corte Europea de Derechos Humanos ha reconocido que el derecho a la privacidad incluye la protección "de la identidad individual física y social, como la identidad de género, nombre, orientación y vida sexual, así como el derecho al desarrollo personal y la autonomía personal"63.

Finalmente, y a propósito del interés superior de los NNA y su derecho a ser oídos, debe tenerse presente que, en el contexto de la CDN, los NNA dejan de ser objetos de política, regulación y protección para pasar a convertirse en

\footnotetext{
${ }^{61}$ UNICEF (2007), p. 115.

${ }^{62}$ Comité de Derechos del Niño, "Observación General № 14 (2013) sobre el derecho del niño a que su interés superior sea una consideración primordial (artículo 3º párrafo 1)", CRC/C/CG/14, párr. 55.

${ }^{63}$ Doek (2006), p. 5.
} 
sujetos de derecho ${ }^{64}$. En este sentido, el art. 3.1 CDN expresa que "En todas las medidas concernientes a los niños que tomen las instituciones públicas o privadas de bienestar social, los tribunales, las autoridades administrativas o los órganos legislativos, una consideración primordial a que se atenderá será el interés superior del niño".

Para evitar que ese interés superior del niño sea dotado de cualquier contenido, la misma CDN -y su práctica- han conferido a los NNA un papel en su determinación (Couso 2006, 148; Lovera 2008, 53-6). Así, la CDN señala que debe garantizarse "al niño que esté en condiciones de formarse un juicio propio el derecho de expresar su opinión libremente en todos los asuntos que afectan al niño, teniéndose debidamente en cuenta las opiniones del niño, en función de la edad y madurez del niño" (art. 12.1) ${ }^{65}$.

Quisiéramos allegar algunas consideraciones finales, luego de lo dicho hasta acá, relativas al derecho de los padres para impartir dirección y orientación a sus hijos. Este derecho, queremos mostrar, no se ve afectado por el reconocimiento del derecho a la identidad de los NNA. Que una ley disponga, como hace el proyecto en comento, que el interés superior del niño va a configurarse, entre otros factores, con la opinión de los NNA -lo que resulta crucial en la preservación de la identidad de estos- no supone que los padres no van a tener ninguna incidencia en el procedimiento específico en que se haga necesario atender a ese interés ${ }^{66}$.

Ello porque, como se sabe, la CDN reconoce el derecho de los padres o representantes legales de NNA a impartir dirección y orientación apropiadas a los NNA. Lo hace en su art. $5^{\circ}$, en los términos siguientes:

Los Estados Partes respetarán las responsabilidades, los derechos y los deberes de los padres o, en su caso, de los miembros de la familia ampliada o de la comunidad, según establezca la costumbre local, de los tutores u otras personas encargadas legalmente del niño de impartirle, en consonancia con

\footnotetext{
${ }^{64}$ Freeman (2006), p. 258; Lovera (2009), pp. 14-16.

${ }^{65}$ Lo mismo sostuvo la Corte IDH, dicho sea de paso, en la OC-24/17:

"Asimismo, esta Corte ha entendido que la debida protección de los derechos de las niñas y niños, en su calidad de sujetos de derechos, debe tomar en consideración sus características propias y la necesidad de propiciar su desarrollo, ofreciéndoles las condiciones necesarias para que vivan y desarrollen sus aptitudes con pleno aprovechamiento de sus potencialidades. En este sentido, las niñas y niños ejercen por sí mismos sus derechos de manera progresiva, a medida que desarrollan un mayor nivel de autonomía personal" (párr. 150).

${ }^{66}$ Así ocurrirá, por ejemplo, en el contexto de un procedimiento judicial en que los padres -sea de consuno o separadamente, según sea el caso- también podrán hacer valer sus pretensiones. LOVERA (2008), pp. 55-56.
} 
la evolución de sus facultades, dirección y orientación apropiadas para que el niño ejerza los derechos reconocidos en la presente Convención.

Ahora bien, este derecho de los padres tiene algunas características que conviene enfatizar. En primer lugar, se trata de un derecho-deber, cuestión que impacta decisivamente en la definición dogmática de sus condiciones de ejercicio. Porque, a diferencia de los derechos "a secas", por llamarlos de alguna manera, donde el titular es libre de determinar cómo se ejercerá ese derecho, acá los padres tienen delimitado el objeto de su ejercicio. ¿En qué consiste del deber? En ofrecer guía y orientación a los NNA a efectos de permitirles la satisfacción de sus derechos, y no, en cambio, para supeditar el ejercicio de esos derechos al consentimiento parental ${ }^{67}$.

En otras palabras, los derechos que la CDN reconoce a los padres $-y$ lo propio ocurre, debe advertirse, a nivel constitucional- se reconocen con respecto al Estado y no sobre los hijos ${ }^{68}$. Es decir, este derecho-deber permite a los padres levantar inmunidad frente al Estado que desee sustituirlos sin razones que así lo justifiquen ${ }^{69}$, mientras que los NNA, por su parte, poseen autonomía progresiva para ejercer sus derechos. En palabras de otros autores:

la responsabilidad parental presupone no solo el ejercicio privilegiado de las funciones de guía y orientación de los padres o representantes legales de los NNA en el curso del progresivo desarrollo de sus derechos ... presupone siempre el que dicha función se ejerza de un modo compatible con el progresivo desarrollo de la autonomía de los $\mathrm{NNA}^{70}$.

A ese ejercicio, por cierto, colaboran sus padres ya sea por medios formales (como escogiendo un establecimiento educacional) o informales (como las enseñanzas en el hogar). Pero no sustituyéndose en los NNA bajo su cuidado. El mismo acercamiento ha abrazado el Tribunal Constitucional, no solo acotando los alcances del derecho preferente de los padres a educar a sus hijos contenido

\footnotetext{
67 Más bien se trata, como anotan Espejo y Lathrop, de no permitir que intereses de terceros, por muy valiosos que sean, restrinjan "ilegítimamente derechos fundamentales del ser humano..." [ESPEJO Y LATHROP (2015), p. 397].

${ }^{68}$ Como acertadamente se ha señalado, dependiendo del tipo de relaciones de que se trate, este derecho-deber puede devenir -en concreto- en derecho, deber o privilegio [ESPEjo (2016)].

${ }^{69}$ El "sin razones que lo justifiquen" que acá se utiliza debe entenderse en el contexto de una multiplicidad de situaciones que van desde la negligencia al abuso, y que gatillan la intervención estatal y de sus agencias. Como se advierte, se trata de situaciones en que los padres o adultos responsables aparecen como los principales agentes violadores de derechos de los NNA y no, en cambio, un rol que asumen en reemplazo de padres y adultos responsables [DAvIS (2011), pp. 163-223].

70 Espejo y Lathrop (2015), p. 411.
} 
en el art. $19 \mathrm{~N}^{0} 10$ i 3 del texto constitucional a la de un derecho-deber ${ }^{71}$, sino, además, cotejando ese derecho-deber de los padres con el ejercicio autónomo de derechos por parte de los NNA. Así, cuando se cuestionó en su sede la regulación que permitía a adolescentes acceder en condiciones de confidencialidad a consejerías en materia de salud reproductiva, el tribunal sostuvo que "Las normas sobre consejería en condiciones de confidencialidad no impiden, en efecto, a los padres de las adolescentes escoger el establecimiento educativo de sus hijas ni transmitir a éstas conocimientos y valores sobre la vida sexual, lo que es suficiente para rechazar el requerimiento en esta parte, sin que dichas normas vulneren el ejercicio legítimo de los derechos de las adolescentes, que también debe ser respetado"72.

Como se ha enfatizado en reiteradas ocasiones, el derecho (a secas) de los padres a guiar el ejercicio de los derechos de sus hijos se encuentra en relación inversamente proporcional al desarrollo de la autonomía (progresiva) de estos. Las palabras del Comité de los Derechos del Niño son más ilustrativas a estos efectos:

El artículo $5^{\circ}$ de la Convención establece que los Estados partes respetarán las responsabilidades, los derechos y los deberes de los padres, los tutores o los miembros de la familia ampliada o de la comunidad, según establezca la costumbre local, de impartir dirección y orientación al niño en su ejercicio de los derechos reconocidos en la Convención. Por consiguiente, el niño tiene derecho a recibir dirección y orientación, que tienen que compensar la falta de conocimientos, experiencia y comprensión del niño y estar en consonancia con la evolución de sus facultades, como se establece en ese artículo. Cuantas más cosas sepa, haya experimentado y comprenda el niño, más deben los padres, tutores $u$ otras personas legalmente responsables del niño transformar la dirección y orientación en recordatorios y consejos y, más adelante, en un intercambio en pie de igualdad. Esta transformación no tendrá lugar en un punto fijo del desarrollo del niño, sino que se producirá paulatinamente a medida que se alienta al niño a aportar sus opiniones.

Esta condición se ve reafirmada por el artículo 12 de la Convención, que estipula que deberán tenerse debidamente en cuenta las opiniones del niño, siempre que el niño esté en condiciones de formarse un juicio propio. En otras palabras, a medida que los niños adquieren facultades

71 Tribunal Constitucional, STC rol № 2787, de 1 de abril de 2015, cons. $6^{\circ}$.

72 Tribunal Constitucional, STC $N^{\circ} 740$, de 18 de abril de 2008, cons. $16^{\circ}$. 
tienen derecho a asumir un nivel cada vez mayor de responsabilidad respecto de la regulación de los asuntos que los afectan ${ }^{73}$.

En definitiva, las relaciones de derechos y deberes que se estructuran a la luz de los antecedentes analizados son las siguientes:

Padres (adultos responsables) - deber -> con NNA bajo su cuidado.

Padres - derecho o privilegio -> frente al Estado para ejercer preferentemente deberes parentales.

NNA - derechos $->$ respecto de padres (adultos responsables) ${ }^{74}$.

NNA - derechos $->$ frente al Estado.

La ley promulgada en noviembre de 2018 -considerando lo dicho hasta acá- tiene algunas notas que debieran Ilamar a la preocupación. Primero, en materia de titularidad del derecho a la identidad de género, esta queda (inconstitucionalmente, nos parece) restringida a los NNA mayores de 14 y menores de 18 años. Para los niños y niñas menores de 14 años, la ley contempla un "Programa de acompañamiento profesional". Dicho programa tiene por finalidad-citamos el art. 23 de la ley promulgada- ofrecer

una orientación profesional multidisciplinaria que incluirá acciones de asesoramiento psicológico y biopsicosocial, cuyo objeto será el otorgamiento de herramientas que permitan su desarrollo integral, de acuerdo a su identidad de género.

El detalle de estos programas queda remitido a la regulación administrativa. Segundo, desconoce legitimidad activa autónoma para los NNA entre 14 y 18 años, supeditando la presentación de la solicitud a "sus representantes legales o algunos de ellos, a elección del mayor de catorce y menor de dieciocho años, si tuviere más de uno" (art. 14). Tampoco contempla la ley un mecanismo para destrabar la oposición entre los NNA, de una parte, y sus representantes legales, de otra. Lo único que se contempla, en una confusa norma, es la obligación de citar de oficio, además de al NNA mayor de 14 y menor de 18 años, "al padre o madre o representante legal que no haya accedido a la solicitud" (art. 16 , inc. $2^{\circ}$ ). Como puede advertirse, se trata de un trámite obligatorio que solo obstaculizará el reconocimiento del derecho a la identidad.

Finalmente, y a propósito del extendido enfoque patologizante, debe anotarse que, si bien la ley reconoce el principio de la no patologización como uno

${ }^{73}$ Comité de los Derechos del Niño (2009). CRC/C/GC/12, párrs. 84-85.

${ }^{74}$ Lo que condiciona el ejercicio de los deberes de padres o adultos responsables con respecto a los NNA a su cuidado, pues esos deberes no pueden ejercerse discrecionalmente. 
fundante de sus regulaciones ${ }^{75}$, contempla la solicitud de algunos antecedentes cuyo mal uso podría terminar frustrando los objetivos declarados de la ley. Así, mientras la solicitud de rectificación de un NNA mayor de 14 y menor de 18 años debe ir acompañada "con claridad y precisión" solo de "los antecedentes de hecho y derecho en que se apoya" (art. 15), faculta enseguida al tribunal para, si lo estima pertinente, ordenar que se acompañen -entre otros- informes psicológicos que den cuenta de la existencia de acompañamiento profesional (art. 17, letra a).

Más problemático resulta aún si se advierte que esta facultad discrecional del tribunal parece encerrar -una vez ejercida- un nuevo requisito, a saber: haber estado en un proceso de acompañamiento psicológico o psicosocial por al menos un año previo a la presentación de la solicitud. Así, se lee en el art. 17 letra a) de la ley que el tribunal podrá ordenar

Un informe psicológico o psicosocial que dé cuenta que el mayor de catorce y menor de dieciocho años y su entorno familiar han recibido acompañamiento profesional por, al menos, un año previo a la solicitud.

\section{Práctica jurisprudencial: Dos enfoques}

Esta sección repasa alguna jurisprudencia reciente en materia de derecho a la identidad de género, con especial énfasis -salvo por alguna excepción- en sentencias dictadas en el contexto de procedimientos de cambio de nombre de conformidad a las Leyes $\mathrm{N}^{\circ} 17.344$ y $\mathrm{N}^{\circ}$ 4.808. El objetivo de esta sección no es dar cuenta de la jurisprudencia disponible -ello excedería con creces su propósito-, sino recurrir a alguna de ella a efectos de identificar los dos acercamientos al derecho a la identidad de género.

\subsection{Una jurisprudencia ambivalente}

En primer lugar, la utilización del procedimiento de cambio de nombre contemplado en las leyes antes identificadas es de reciente data. A falta de legislación encargada de reconocer la identidad de género, las personas trans recurren a este procedimiento como un sucedáneo que les permita avanzar (apenas) en alguna de las dimensiones del reconocimiento que abarca el derecho a la identidad ${ }^{76}$. Ello explica, creemos, la ambivalencia que es posible detectar

\footnotetext{
${ }^{75}$ Dispone el artículo $5^{\circ}$, letra a), que se reconoce y protege "el derecho de toda persona trans a no ser tratada como enferma". Del mismo modo, el artículo 17, inc. $6^{\circ}$, establece la prohibición absoluta de poder "decretar la realización de exámenes físicos al mayor de catorce y menor de dieciocho años".

${ }^{76}$ EsPejO Y LATHROP (2015), pp. 395-396.
} 
en la jurisprudencia al respecto. En cualquier caso, las sentencias que acá se muestran -sin que se pretenda ofrecer un barrido estadístico ${ }^{77}$ - nos ayudan a advertir los dos enfoques dominantes. Uno, en colisión con el reconocimiento al derecho a la identidad desde un enfoque de derechos, que patologiza a las personas trans y que aborda sus demandas como asuntos médicos. Otro, más alentador, que reconoce -aunque de modo todavía limitado, como se dirá- el derecho de las personas a obtener protección legal, apenas incipiente y de manera muy acotada, en alguna de las dimensiones del derecho a la identidad de género.

\section{A. ¿Un enfoque de derechos?}

Hay acercamientos que, en línea con lo que acá se ha venido diciendo, se aproximan adecuadamente a la comprensión de la identidad de género con un enfoque de derechos. Así, la Iltma. Corte de Apelaciones de Santiago ha sostenido que "ha quedado en evidencia que no es la existencia de los órganos sexuales lo que hace a una persona sentirse e identificarse bajo un género u otro, sino el sentimiento de identidad sexual percibido durante su desarrollo vital, que se ha probado suficientemente en autos a través de documentos provenientes de profesionales competentes y declaración de testigos, lo que se confirma con actos positivos efectuados por su parte tendientes a adaptar su cuerpo (... $)^{\prime \prime 78}$.

No hay antecedentes en la sentencia de la corte referidos a la importancia que habría asignado a los informes médicos que se acompañaron durante la vista de la causa en primera instancia, tales como un certificado que da cuenta de que el requirente se encontraba en lista de espera para efectos de una cirugía de reasignación de sexo o el que acreditaba que se encontraba ingresado en un programa de salud mental.

¿Por qué es relevante esto? Porque algunas decisiones judiciales han rechazado la solicitud de cambio de nombre precisamente por no haberse arribado a la convicción de que el solicitante, efectivamente, experimentaba o había vivenciado o vivía una identidad diversa a la del sexo que se le ha asignado al nacer.

\section{B. Un enfoque patologizante}

El enfoque patologizante asume que las personas trans que se acercan a solicitar el cambio de nombre de modo que este se adecúe a su identidad de

77 MuÑOZ (2015).

78 Corte de Apelaciones de Santiago, rol No 9901-2014, de 9 de marzo de 2015, cons. $3^{\circ}$. 
género, lo hacen todas desde lo que antes denominamos, de modo tentativo, disconformidad (sexo/género) como incomodidad. Es decir, para este enfoque la transexualidad es equivalente a un trastorno $y$, en tanto tal, necesitado de acreditación médica ${ }^{79}$ o terapéutica ${ }^{80}$. Por ejemplo, un juzgado de letras de Arica sostuvo -para rechazar la demanda- que "teniendo presente además lo dispuesto en el ya citado artículo 31 de la Ley No 4.808, y el concepto de identidad de género precisado en el considerando tercero del presente fallo, ha de señalar el juzgador que no se ha aportado en autos ningún antecedente médico, psicológico o psiquiátrico que apoye, sustente o sirva de fundamento para lo solicitado en el primer otrosí de la demanda de fojas 1, es decir, que den cuenta a este tribunal de la concurrencia en el solicitante de la vivencia interna e individual que constituye la identidad de género, pues sólo tales antecedentes permitirían al tribunal concluir que don (...) no solo se viste y presenta ante todos como una mujer, sino que se siente e identifica con el sexo femenino" ${ }^{\prime \prime 1}$.

Por supuesto que el indicador de acercamiento patologizante dista de reducirse al solo rechazo de la demanda, puesto que es posible advertirlo, también, en aquellas sentencias que acogen las solicitudes. En efecto, se ha exigido el mismo tipo de pruebas médicas a efectos de acoger las solicitudes de cambio de nombre. Vale la pena transcribir acá un considerando de un tribunal de letras que, acogiendo la solicitud, se aproxima al asunto, sin embargo, con un fuerte sesgo patologizante:

Que de otra parte y atendidas las características de la solicitud de marras, correspondía al solicitante acompañar prueba suficiente y pertinente que refrendara su pretensión, en el sentido de que tanto física como psicológicamente es una persona del género opuesto al que figura en su inscripción de nacimiento, lo que es posible desprender del análisis conjunto de las deposiciones de los testigos y del informe psicológico agregado a fojas 26, en el que se concluye respecto del solicitante, que existe la presencia de una identidad de género femenina, desde su infancia, en las dimensiones psicológica, cognitiva, emocional y social de su personalidad, identidad que se fue conformando desde su infancia y hasta terminada su adolescencia y en la actual etapa adulta se manifiesta sin ningún tipo de conflicto psicológico, manteniendo relaciones afectivas con hombres heterosexuales de larga duración, integrándose en comunidades religiosas y deportivas, llevando un estilo de vida sano y con mucha vida socia/ ${ }^{32}$.

\footnotetext{
79 Regueiro De Giacomi (2012), pp. 105-6; Ravetllat (2017), pp. 49-50.

80 Ravetllat (2018), p. 413.

$811^{\text {er }}$ Juzgado de Letras de Arica, rol Interno V-320-2015, de 6 de mayo de 2016, cons. $7^{\circ}$.

$821^{\text {er }}$ Juzgado de Letras Civil de Antofagasta, rol Interno $N^{\circ}$ V-303-2015, de 6 de abril de 2016, cons. $10^{\circ}$.
} 
En sentido similar se han acogido solicitudes en las que la cirugía de readecuación de sexo ha sido fundamental para el tribunal. Así, el Juzgado de Letras de Peñaflor, a pesar de reconocer que el sexo -a efectos de las consideraciones de la legislación vigente- no puede solo limitarse a la constatación de la existencia de órganos sexuales, sostuvo: "lo anterior [su identidad de género] se confirma con actos positivos efectuados por la solicitante tendientes a adaptar su identidad sexual al género que desea se le reconozca, lo que consta a través de informe médico que rola a fojas 8 y que da cuenta que la requirente se efectuó una cirugía genital de readecuación sexual, y que se encuentra en tratamiento hormonal de reemplazo, sumado todo ello a su imagen femenina y el uso de un nombre correspondiente a ésta" ${ }^{\prime 3}$.

\subsection{El caso de los NNA}

En materia de NNA, la jurisprudencia chilena es bastante más reducida. Dos casos son objeto de análisis aquí. El primero, relativo a un procedimiento de cambio de nombre y partida de nacimiento de una niña trans ${ }^{84}$. El segundo, un recurso de protección en el que se solicita a un organismo privado (en este caso, una clínica) reconocer y utilizar, para todos los efectos, el nombre social de una niña trans. Con respecto al procedimiento de cambio de nombre, una niña trans de 5 años solicitaba la adecuación de su nombre a su identidad de género. Cabe destacar la forma en que el tribunal se acercó a la identificación legal del sexo para efectos de las leyes antes señaladas. Descansando en un fuerte enfoque de derechos, sostuvo que el sexo "no puede reducirse al examen visual de los genitales al momento de nacer pues, evidentemente, la sexualidad del ser humano es mucho más compleja y requiere contemplar otro tipo de antecedentes que conforman la identidad del individuo, no debiendo ser determinante un examen que se reduce a la genitalidad" ${ }^{\prime 25}$.

${ }^{83}$ Juzgado de Letras de Peñaflor, rol Interno N V-9-2016, de 21 de junio de 2016, cons. $4^{\circ}$. Debe anotarse, con todo, que estas declaraciones son matizadas, mas no deben pasarse por alto, con declaraciones que apuntan a una suerte de enfoque de derechos. Suerte de enfoque de derechos, pues, a decir del tribunal, esto -el reconocimiento de la identidad de género de la solicitante- parece ser más una cuestión inescapable que una de autonomía:

En consecuencia, su identidad de género no puede ser desconocida y a objeto que pueda alcanzar el pleno desarrollo de su personalidad sin discriminación y en resguardo de su integridad psíquica y física, con respeto a su vida privada como a su honra, se accederá al cambio de sexo en la partida de nacimiento respectiva conforme a la facultad conferida por el artículo 17 de la Ley $N^{\circ} 4.808$ (cons. $4^{\circ}$ ).

${ }^{84}$ La sentencia de este caso se encuentra en poder de los autores de este trabajo, siendo facilitada por la familia involucrada para fines académicos. Por involucrar antecedentes sensibles, nos reservamos la identificación de la causa que, para todos los efectos, será sindicada como M.

${ }^{85} \mathrm{M}$. 
Es cierto que acá el tribunal descansa, como se advierte de los considerandos de la sentencia, en prueba pericial. Del tipo de pruebas periciales que, tratándose de adultos, llevarían a patologizar su demanda de reconocimiento. ¿Debe descartarse este tipo de pruebas tratándose de NNA? No necesariamente. Es posible y hasta cierto punto aconsejable que, en casos de NNA, los tribunales puedan recurrir a pruebas periciales o a otro tipo de antecedentes de probanzas. Ahora bien, ¿con qué objetivo? ¿Para efectos de calificar-como ocurre en el acercamiento patologizante- la correspondencia médica de la identidad de género? No. Pero sí para efectos de allegar herramientas que le permitan al tribunal mejor evaluar el grado de madurez y desarrollo del NNA y, con ello, a mejor calibrar el espacio de autonomía que debe asegurársele ${ }^{86}$. Antes de correr el riesgo de que los tribunales terminen reemplazando el interés superior del niño por lo que el juez o la jueza de turno crea que este importa -sobre esto hay experiencias-, se prefiere echar mano a instrumentos que ayuden a abrir espacios de autonomía para el ejercicio de los derechos fundamentales involucrados.

¿Ocurre eso en este caso? Difícil afirmarlo. Buenas intenciones aparte y reconociendo que la decisión de acoger bien puede ser vista como un ejercicio de justicia material, la sentencia recurre a las pruebas periciales -psiquiátricas y psicológicas- a efectos de identificar una "disforia de género infantil" ${ }^{27}$. Si bien inmediatamente de identificado el diagnóstico -esto no debe perderse de vista: es un diagnóstico- se echa mano a los "Principios de Yogyakarta" para sostener una versión adecuada desde el enfoque de derechos de la identidad de género, la sentencia asume -equivocadamente, como se ha venido argumentando acá- que aquella es únicamente consecuencia de un "trastorno de identidad que [se] sufre..." 88 .

Este enfoque nos parece inapropiado, pues refuerza un imaginario social de sufrimiento de la niña por ser trans, en circunstancias en que el eventual sufrimiento de una persona trans no deriva de esa condición, sino de diversas situaciones en las que son (o pueden ser) vulnerados sus derechos, situación particularmente grave tratándose de alguien que aún está en crecimiento.

El segundo caso se refiere a un recurso de protección presentado por una niña trans y su madre. De acuerdo a los hechos del caso, una madre y su hija trans habían solicitado en un recinto hospitalario la modificación del nombre e identidad contenidos en la ficha clínica de la niña, con el objeto de hacerlos coincidentes con su identidad social. Frente a la negativa injustificada de la

86 LOVERA (2008), pp. 56-60.

${ }_{87} \mathrm{M}$.

${ }_{88} \mathrm{M}$. 
adecuación, reclamaron la afectación del derecho a la igualdad y la privacidad $^{89}$. La decisión invoca la protección constitucional de la dignidad, así como referencias generales a "las garantías constitucionales de igualdad ante la ley, la igual protección de la ley en el ejercicio de sus derechos, el respeto y protección a la vida privada y a la honra de la persona y su familia ..."

Advirtiendo que un juzgado civil ya había autorizado la rectificación de la partida de nacimiento de la niña, cita, enseguida, algunas disposiciones del derecho internacional de los derechos humanos relativas al derecho a la igualdad y el interés superior de los niños. Agrega que "el derecho al completo y total desarrollo de la personalidad va de la mano con un concepto primordial que constituye la base de todos los principios y derechos... cual es el de la dignidad de la persona" ${ }^{\prime \prime 1}$. Finalmente, la sentencia ofrece una lectura (adecuada) amplia del derecho al desarrollo de los NNA, entendido "como un concepto holístico que abarca el desarrollo físico, mental, espiritual, moral, psicológico y social del niño". Pese a todo lo anterior, la corte acoge el recurso sobre la base de considerar que, al haber existido una sentencia ejecutoriada que autorizaba la rectificación de la partida, el recinto hospitalario había actuado de manera infundada.

\section{Políticas públicas}

A falta de legislación que reconozca el derecho a la identidad de género, los gobiernos pueden avanzar en el reconocimiento y trato con igual respeto y consideración de sus ciudadanas y ciudadanos a partir de la dictación de regulaciones administrativas que se encarguen de ofrecer espacios de reconocimiento en diferentes ámbitos cruciales del desarrollo de la vida de las personas y, como ocurre en el ámbito educacional, de NNA. Como se ha venido diciendo acá, uno de los principales problemas para el pleno reconocimiento del derecho a la identidad de las personas trans radica en la falta de legislación específica que aborde el derecho a la identidad de género. El recurso interpretativo al que se ha echado mano, de otra parte, sea de disposiciones constitucionales o de las regulaciones civiles registrales, si bien han permitido avances relevantes, está lejos de ofrecer una respuesta enteramente satisfactoria desde el punto de vista del reconocimiento. Ello abre espacio para que la Administración del Estado

\footnotetext{
${ }^{89} \mathrm{Al}$ igual que en el caso anterior, esta decisión -en poder de los autores de este trabajo por entrega efectuada por la familia -también involucra datos sensibles. Para todos los efectos, esta decisión se identificará como D.

90 D.

91 D.
} 
pueda concurrir a la protección de derechos constitucionales por medio de su actividad interpretativa y de implementación de la legislación ${ }^{92}$, más aún cuando la legislación aprobada en el segundo semestre de 2018 adolece de ciertas imperfecciones, especialmente al invisibilizar a niños y niñas menores de 14 años como sujetos de derecho.

Ahora bien, en el caso de Chile, en particular, podemos pensar en los desarrollos en materia de salud, educación y justicia.

En la primera de estas áreas, podemos dar cuenta de un trabajo progresivo que viene desarrollando el Ministerio de Salud para avanzar en la protección de la identidad de personas trans. En concreto, con la Circular N ${ }^{\circ} 21$, de 14 de junio de 2012, se reiteraron instrucciones para la atención en la red asistencial que incluyen el uso del nombre social y género con que la persona se identifica por parte de los establecimientos de atención primaria y especializada, así como la incorporación del nombre social en los registros, enfatizando la identidad de la persona para el trato debido.

Esta circular vino a reemplazar a la № 34, de 13 de septiembre de 2011, que usaba un lenguaje patologizante al hablar de "trastorno de identidad de género" y no mandataba el uso del nombre social, sino que solo lo sugería. No refiriéndose ninguna de estas circulares de forma expresa a los niños, niñas y adolescentes, sí se les consideró expresamente desde la posible condición de personas intersex. Así, por la Circular № 18, de 22 de diciembre de 2015, se instruyó sobre ciertos aspectos de la salud a niños y niñas intersex, entendiendo allí por tales a quienes tienen un sexo indeterminado que apunta a la futura creación de un protocolo con una mirada interdisciplinaria en lo sanitario, pero que desde ya establece la instrucción para detener los tratamientos de normalización, incluyendo cirugías irreversibles, hasta que tengan edad suficiente para decidir sobre sus cuerpos.

En el área de la educación, en tanto, y amparada en su mandato legal y constitucional, la Superintendencia de Educación ha emitido algunas normas administrativas entra las que debemos destacar el Ordinario $N^{0} 768$, de 27 de abril de 2017, regulador de los derechos de niños, niñas y estudiantes trans en el ámbito de la educación ${ }^{93}$.

\footnotetext{
92 TAYLOR (2007).

93 Antes se había dictado el Ordinario № 476, de 29 de noviembre de 2013, como instructivo para los establecimientos educacionales sobre Reglamento Interno, en lo referido a Convivencia Escolar. En su punto $\mathrm{N}^{\circ}$ 8, letra m), establecía que contravienen la normativa educacional las disposiciones en dichos reglamentos que establezcan criterios o tratos discriminatorios de carácter arbitrario en relación con los alumnos y alumnas de un establecimiento educacional, fundados en su orientación sexual o identidad de género.
} 
La reglamentación que comentamos se estructura en una primera parte, dedicada a dar unas definiciones (identidad de género, expresión de género y trans), para posteriormente señalar principios orientadores para la comunidad educativa respecto a los niños, niñas y estudiantes trans, a saber: dignidad del ser humano; interés superior del niño, niña y adolescente; no discriminación arbitraria, y buena convivencia escolar. En tercer lugar, enumera los derechos que asisten a los niños, niñas y estudiantes trans: a acceder o ingresar a los establecimientos educacionales, a través de mecanismos de admisión transparentes y acordes a la normativa vigente; a permanecer en el sistema educacional formal; a ser evaluados y promovidos mediante procedimientos objetivos y transparentes de igual manera que sus pares, sin que el ser una persona trans implique discriminaciones arbitrarias que afecten este derecho; a recibir una educación que les ofrezca oportunidades para su formación y desarrollo integral, atendiendo especialmente a las circunstancias y características del proceso que les corresponde vivir; a participar, a expresar su opinión libremente y a ser escuchados en todos los asuntos que les afectan, en especial cuando tienen relación con decisiones sobre aspectos derivados de su identidad de género; a recibir una atención adecuada, oportuna e inclusiva en el caso de tener necesidades educativas especiales, en igualdad de condiciones que sus pares; a no sufrir discriminación arbitraria por el Estado ni por las comunidades educativas en ningún nivel ni ámbito de su trayectoria educativa; a que se respete su integridad física, psicológica y moral, no pudiendo ser sujeto de tratos vejatorios o degradantes por parte de ningún miembro de la comunidad educativa; a estudiar en un ambiente de respeto mutuo, con un trato digno e igualitario en todos los ámbitos, en especial en el de las relaciones interpersonales y de la buena convivencia, y a expresar la identidad de género propia y su orientación sexual. De cara a la efectividad de tales derechos, resulta interesante pensar en herramientas que ayuden a ese fin. En esa línea estimamos que se debe enmarcar la implementación de cualquier campaña contra el bullying, por ejemplo, manifestado en el ciberacoso. La estrategia "hay palabras que matan" ${ }^{\prime 94}$ del segundo semestre de 2018, promovida por el Ministerio de Educación, debería poner atención a la infancia y adolescencia trans.

En algo que debe destacarse, este ordinario establece las obligaciones que corresponderán a los sostenedores y directivos de los establecimientos educacionales, que consisten en respetar dichos derechos y tomar las medidas necesarias para su efectividad. Se instruye para que tomen las medidas administrativas, sociales y educativas apropiadas para proteger y garantizar los derechos de los niños, niñas y estudiantes contra toda forma de acoso discriminatorio, tales

${ }^{94}$ Ministerio de Educación (2018). 
como prejuicios, abuso físico o mental, trato negligente, vulneración de su intimidad o privacidad y/o malos tratos, velando por el resguardo de su integridad psicológica y física, y para dirigir todas las acciones necesarias que permitan su erradicación en el ámbito educativo.

En la quinta parte se establece y regula un procedimiento interno en cada establecimiento para el reconocimiento de la identidad de género de estudiantes en que, entendemos, deberá velarse por el cumplimiento de los principios rectores de infancia, especialmente la participación, la no discriminación y el interés superior, hoy consagrados también en la nueva normativa sobre identidad de género.

La parte sexta se refiere a ciertas medidas básicas de apoyo que se contemplan para ser adoptadas por las instituciones educativas, como son el apoyo a la niña o niño estudiante y a su familia; la orientación a la comunidad educativa; el uso del nombre social en todos los espacios educativos; el uso del nombre legal en documentos oficiales; el derecho del niño o niña estudiante para utilizar el uniforme, ropa deportiva y/o accesorios que considere más adecuados a su identidad de género, independientemente de la situación legal en que se encuentre, y la utilización de los servicios higiénicos de acuerdo a las necesidades propias del proceso que esté viviendo, respetando su identidad de género.

Sin duda, cada uno de los apartados de este ordinario deberán conjugarse con el procedimiento de acompañamiento que prevé la ley promulgada en Chile en 2018, que, además, optó por otra definición de identidad de género, a diferencia de los desarrollos que acá comentamos. En efecto, dice la ley que se entenderá por identidad de género la convicción personal e interna de ser hombre o mujer, tal como la persona se percibe a sí misma, la cual puede corresponder o no con el sexo y nombre verificados en el acta de inscripción del nacimiento. Se trata, así, de una definición que binariza el género ${ }^{95}$.

En contra de esta reglamentación se interpusieron algunas acciones de protección, en las que se reclamó el desconocimiento, amenaza y perturbación de la libertad de conciencia de los NNA. Estas acciones fueron rechazadas. Para ello, la Corte de Apelaciones de Santiago sostuvo que las instrucciones se habían dictado en cumplimiento -la corte se refiere al deber del Estado de promover y

\footnotetext{
95 No hay espacio en este trabajo para abordar este aspecto, pero, debe anotarse que los desarrollos constitucionales más recientes, en latitudes tan diversas como Australia, Alemania e India, dan cuenta de una acertada problematización (desde el enfoque de derechos y el reconocimiento de derechos a la personalidad) del binarismo. Al respecto, véase, High Court of Australia, NSW Registrar of Births, Deaths and Marriages v Norrie [2014] HCA 11, de 2 de abril de 2014; The Supreme Court of India, National Legal Services Authority v Union of India and Others, de 15 de abril de 2014; Tribunal Constitucional Federal Alemán, 1 BvR 2019/16, de 10 de octubre de 2017; Corte Constitucional de Austria, E 2918/2016-29, de 14 de marzo de 2018.
} 
respetar los derechos fundamentales ${ }^{96}$ - del mandato que impone la Ley General de Educación, conforme al que "[e]l sistema propenderá a eliminar todas las formas de discriminación arbitraria que impidan el aprendizaje y la participación de los y las estudiantes" ${ }^{\prime \prime 7}$. Junto con destacar que la reglamentación en cuestión se inspiraba en "un concepto integral de los derechos humanos, en que los mismos no se limitan a reconocer y amparar un catálogo de derechos y garantías reconocidos constitucionalmente en forma taxativa" ${ }^{\prime \prime 8}$, la corte citó de manera expresa el razonamiento de la Corte Interamericana de Derechos Humanos en el caso Atala -antes indicado-. Conforme a este, la identidad de género es uno de los criterios sobre los que se encuentra proscrita la discriminación ${ }^{99}$.

Por último, la corte se refiere -acertadamente- al deber estatal de considerar siempre al interés superior del niño como un principio orientador de su política. La realización de este principio, prosigue, lo lleva a evitar que al interior de las comunidades escolares los niños, niñas y estudiantes con una sensibilidad de género diversa a aquella que corresponde a su sexo biológico puedan ser (...) discriminados por aquella orientación; persiguiendo de esta forma su incorporación en igualdad de derechos y deberes con el resto de los miembros de éstas [sic] comunidades a través de derechos reconocidos y las medidas adoptadas $(. . .)^{100}$.

Finalmente, en el área, ahora, de la justicia, el trabajo realizado desde la Cumbre Judicial Iberoamericana - de la que forma parte el Poder Judicial chileno- ha dado alguna cabida a una preocupación por las particularidades que ha de tener el abordaje judicial de asuntos que involucran a niños y niñas. Para ello se ha elaborado el Ilamado Protocolo Iberoamericano de Actuación Judicial para mejorar el acceso a la justicia, centrado en las personas con discapacidad; migrantes; niños, niñas y adolescentes; comunidades, y pueblos indígenas.

Este Protocolo Iberoamericano, con especial énfasis en justicia con enfoque de género se divide en dos volúmenes, el relativo a niñas, niños y adolescentes; personas, comunidades y pueblos indígenas; personas con discapacidad

${ }^{96}$ Corte de Apelaciones de Santiago, rol No 39836-2017 (ACUM. 39.837-2017), de 5 de octubre de 2017, cons. $13^{\circ}$.

${ }_{97}$ Corte de Apelaciones de Santiago, rol № 39836-2017 (ACUM. 39.837-2017), de 5 de octubre de 2017, cons. $9^{\circ}$.

${ }_{98}$ Corte de Apelaciones de Santiago, rol No 39836-2017 (ACUM. 39.837-2017), de 5 de octubre de 2017, cons. $11^{\circ}$.

${ }^{99}$ Corte de Apelaciones de Santiago, rol No 39836-2017 (ACUM. 39.837-2017), de 5 de octubre de 2017, cons. $12^{\circ}$.

${ }^{100}$ Corte de Apelaciones de Santiago, rol № 39836-2017 (ACUM. 39.837-2017), de 5 de octubre de 2017, cons. $14^{\circ}$. 
y migrantes, y el relativo a mujeres víctimas de violencia. El primer volumen del protocolo es un documento fundado en instrumentos internacionales de derechos humanos que: a. Prioriza los principios y prácticas dirigidos tanto a la modificación de aspectos jurídicos como a los administrativos relacionados con la atención en el ámbito judicial de personas y colectivos en situación de vulnerabilidad; b. Facilita que las personas que participan en el funcionamiento de los sistemas judiciales cuenten con una herramienta de consulta que sirva de guía de actuación, avanzando así en la observancia de los estándares más protectores y en la consideración de las características y situación de los grupos y personas, antes mencionados; c. Favorece que las personas y grupos sociales conozcan y ejerzan con plenitud, ante el sistema de justicia, los derechos reconocidos por el ordenamiento jurídico internacional; d. Propicia el diálogo entre cortes, en la medida en que retoma sentencias y buenas prácticas que muestran cómo se están protegiendo los derechos de personas y colectivos en tribunales internacionales y en los poderes judiciales de la región. El impulso dado por la cumbre ha significado que desde febrero de 2018 el Poder Judicial chileno cuente con una política institucional sobre igualdad de género y no discriminación. En el ámbito se la infancia, en tanto, en el mes de noviembre del mismo año, el pleno de la Excelentísima Corte Suprema acordó que, en la reformulación del plan estratégico vigente para 2021-2025, la temática de infancia será incorporada como forma de avanzar hacia una política que favorezca la efectividad de sus derechos.

\section{Conclusiones}

El reconocimiento del derecho a la identidad de género de los NNA está en consonancia con las obligaciones internacionales que el Estado de Chile ha adquirido soberanamente frente a organismos internacionales y frente a las demás naciones. Desde luego que la incorporación del derecho a la identidad de género de los NNA no solo permitirá responder a esas obligaciones, sino que, de paso, nos conferirá una ley que permita brindar un adecuado reconocimiento y protección a los NNA, colocando al país -y en esto no solemos hacer noticia-a la vanguardia de las leyes de protección de la niñez y la adolescencia ${ }^{101}$.

\footnotetext{
101 Con todo, deben anotarse experiencias que, a este respecto, ya están bastante avanzadas. Tal es el caso del art. $6^{\circ}$, inc. $1^{\circ}$, del Código de los Niños y Adolescentes del Perú (Ley № 27.337), que dispone: "El niño y el adolescente tienen derecho a la identidad, lo que incluye el derecho a tener un nombre, a adquirir una nacionalidad y, en la medida de lo posible, a conocer a sus padres y llevar sus apellidos. Tienen también derecho al desarrollo integral de su personalidad".

El art. 12 del Código de la Infancia y la Adolescencia de Colombia, por su parte, dispone que en la aplicación del mismo se observará una perspectiva de género, que define como "el reconocimiento
} 
En este trabajo hemos propuesto que el reconocimiento de la identidad de género de NNA, para ser consistente con los derechos de autonomía que recoge el texto constitucional, debe hacerse desde un enfoque de derechos que llama a dejar proscritas todas las posibles miradas patologizantes que profundizan los efectos negativos de la falta de reconocimiento y abonan bien el espacio para las vulneraciones de derechos en contextos como la familia, la escuela o el vecindario. Los efectos de la falta de reconocimiento se pueden ver en situaciones cotidianas: entrar a un baño, solicitar asistencia sanitaria, salir o entrar del país, usar la credencial estudiantil para subir a una micro, o en situaciones judiciales como la relación directa y regular con padres que no respeten la identidad, el trato en audiencias, las derivaciones al Sename, los sistemas de guarda.

Además, reconocer este derecho es indispensable para hacer efectivo el pleno y libre ejercicio de otros derechos, esenciales para que niños, niñas y adolescentes desplieguen sus potencialidades, como son, por ejemplo, el nombre, la imagen, la vida privada, su integridad psíquica y, por cierto, su derecho a ser oído. Hablamos, así, de un impacto directo en derechos de carácter personalísimo, cuyo ejercicio para las personas menores de 18 años no puede afectarse por consideraciones que bien podemos calificar de "adultocéntricas", como aquellas patologizantes que antes hemos presentado.

En último término, lo que se pone en juego con el reconocimiento de su identidad de género es el derecho a contar con oportunidades de supervivencia (¿no es lo mínimo que podemos reclamar al derecho?), crecimiento y desarrollo en un contexto de bienestar físico, emocional y social al máximo de sus posibilidades ${ }^{102}$, lo cual tiene un impacto directo en la salud integral de niños, niñas y adolescentes. Como ha dicho el comité, el derecho del niño a la salud, definido en el artículo 24 de la CDN, es un derecho inclusivo que no solo abarca la prevención oportuna y apropiada, la promoción de la salud y los servicios paliativos, de curación y de rehabilitación, sino que también incluye el derecho del niño a crecer y desarrollarse al máximo de sus posibilidades y vivir en condiciones que le permitan disfrutar del más alto nivel posible de salud. El enfoque integral en materia de salud sitúa la realización del derecho del niño a la salud en el contexto más amplio de las obligaciones internacionales en materia de derechos humanos ${ }^{103}$.

Para lograr la plena realización del derecho de todos los niños a la salud, los Estados tienen la obligación de asegurar que la salud del niño no quede minada

de las diferencias sociales, biológicas y psicológicas en las relaciones entre las personas según el sexo, la edad, la etnia y el rol que desempeñan en la familia y en el grupo social".

102 Comité de los Derechos del Niño (2013). CRC/C/GC/15, párr. 1.

103 Comité de los Derechos del Niño (2013). CRC/C/GC/15, párr. 2. 
por la discriminación que le pueda afectar por cualquier condición, tal como lo es la identidad de género, importante factor que contribuye a la vulnerabilidad y a fenómenos graves como los estereotipos y las consecuencias negativas de ellos, o a prácticas y normas de comportamiento nocivas basadas en el género que están arraigadas en las tradiciones y costumbres ${ }^{104}$.

Como hemos expuesto, no hay razones desde los antecedentes normativos y científicos para desconocer el derecho a la identidad de género de niños, niñas y adolescentes. Ellos y ellas no solo son titulares del derecho a la identidad de género, sino que pueden y deben ejercer su derecho a la identidad de género sin más limitaciones que las que imponen sus propios desarrollo y autonomía progresivas en su trayectoria de vida, siendo un imperativo para el Estado y sus poderes, así como para cada padre, madre o adulto responsable, velar por el interés superior cumpliendo todas las garantías y salvaguardias debidas, a fin de procurar así la eliminación de todas las formas de exclusión que hoy afectan a los niños y niñas trans en Chile.

\section{Bibliografía CitADA}

Aldunate Lizana, Eduardo (2008): Derechos fundamentales (Santiago, LegalPublishing).

American Psychiatric Association (2013): Diagnostic and Statistical Manual of Mental Disorders (DSM-5), $5^{\text {a }}$ edición (Arlington, APA).

Carballo Vargas, Sonia (2002): "Educación de la expresión de la sexualidad humana", en: Revista Educación (Vol. 26, Nº 001), pp. 29-46.

(2006): "Educación de la expresión de la sexualidad y la inteligencia emocional en niños, niñas y adolescentes con derechos", en: Revista Actualidades Investigativas en Educación (Vol. 6, № 3), pp. 1-14.

Cea Egaña, José (2012): Derecho constitucional chileno, $2^{a}$ edición (Santiago, Ediciones Universidad Católica de Chile), Tomo II.

Centro latinoamericano de Sexualidad y Derechos Humanos, Instituto de Medicina Social, Universidad del Estado de Río De Janeiro (2007): Chile: Panorama de sexualidad y derechos humanos (Santiago-Río de Janeiro, CLAM).

COMISIÓN INTERAMERICANA De DereChos Humanos (2015): Violencia contra personas LGBTI, DOC. OAS/Ser.L/V/II.rev.1.

COUPET, Sacha (2015): "Policing Gender on the Playground: Interests, Needs, and Rights of Transgendered and Gender Non-conforming Youth", en: Coupet,

${ }^{104}$ Comité de los Derechos del Niño (2013). CRC/C/GC/15, párrs. 8-10. 
Sacha, y Marrus, Ellen (editoras), Children, Sexuality, and the Law (Nueva York, NYU Press), pp. 183-223.

COUSO SALAS, Jaime (2006): “El niño como sujeto de derechos y la nueva justicia de familia. Interés superior del niño, autonomía progresiva y derecho a ser oído", en: Revista de Derechos del Niño (№ 3-4), pp. 145-166.

Davis, Samuel (2011): Children's Rights Under the Law (Nueva York, Oxford University Press).

Doek, Jaap (2006): A commentary on the United Nations Convention on the Rights of the Child: Article 8 The Right to Preservation of Identity, Article 9 The Right not to be Separated from his or her Parents (Leiden-Boston, Martinus Nijhoff Publishers).

Erazo Latorre, Ximena; Gauché Marchetti, Ximena, y Jara León, José (2015): Derechos humanos, diversidad sexual y políticas públicas en América Latina (Santiago, Ediciones LOM).

EsPejO, Nicolás (2016): "El derecho a la vida familiar, los derechos del niño y la responsabilidad parental", en: Lepin, Cristián, y Gómez de la Torre, Maricruz (coordinadores), Estudios de derecho familiar I (Santiago, Thomson Reuters), pp. 197-209.

Espejo Yaksic, Nicolás, y Lathrop Gómez, Fabiola (2015): "Identidad de género, relaciones familiares y derechos de niños, niñas y adolescentes. Comentarios al proyecto de ley que reconoce y da protección al derecho a la identidad de género", en: Revista de Derecho UCN (Coquimbo) (Vol. 22, № 2), pp. 393-418.

Fernández Sessarego, Carlos (1992): Derecho a la identidad personal (Buenos Aires, Astrea).

FrankE, Katherine (1995): "The Central Mistake of Sex Discrimination Law: The Disaggregation of Sex from Gender", en: University of Pennsylvania Law Review (Vol. 144, № 1), pp. 1-100.

Fraser, Nancy (1999): "Social Justice in the age of Identity Politics: Redistribution, Recognition, and Participation", en: Ray, Larry, y Sayer, Andrew (editores), Culture and Economy after the Cultural Turn (Londres-Thousand Oaks-Nueva Delhi, Sage Publications), pp. 25-52.

Freeman, Michael (2006): "Tomando más en serio los derechos de los niños", en: Revista de Derechos del Niño (№ 3-4), pp. 251-279.

Gauche Marchetti, Ximena (2011): Sexualidad diversa y discriminación. Una mirada desde el derecho internacional de los derechos humanos (Saarbrücken, Editorial Académica Española). 
Gómez Bernales, Gastón (2005): Recurso de protección y derechos fundamentales (Santiago, Ediciones Universidad Diego Portales).

Greenawalt, Kent (2006): Religion and the Constitution (Nueva Jersey-Oxford, Princeton University Press), Vol. 1: Fairness and Free Exercise.

Honneth, Axel (1997): La lucha por el reconocimiento. Por una gramática moral de los conflictos sociales (Traducc. Manuel Ballestero Barcelona, Crítica-Grijalbo Mondadori).

Lovera Parmo, Domingo (2008): "Razonamiento judicial y derechos del niño: De ventrílocuos a marionetas", en: Justicia y Derechos del Niño ( $\left.\mathrm{N}^{\circ} 10\right)$, pp. 45-62. (2009): “Niño, adolescente y derechos constitucionales: De la protección a la autonomía", en: Justicia y Derechos del Niño (№ 11), pp. 11-54.

(2015): "Igualdad y no discriminación de niños, niñas y adolescentes: Necesidad de un sistema de garantías reforzadas", en: Serie Los derechos de los niños, una orientación y un límite ( $\left.\mathrm{N}^{\circ} 3\right)$. Disponible en: http://unicef.cl/ web/los-derechos-de-los-ninos-una-orientacion-y-un-limite-igualdad-y-nodiscriminacion-de-ninos-ninas-y-adolescentes-necesidad-de-un-sistema-degarantias-reforzadas/ [visitado el 3.12.2018].

MarShall, Jill (2009): Personal Freedom through Human Rights Law? Autonomy, Identity and Integrity under the European Convention on Human Rights (LeidenBoston, Martinus Nijhoff Publishers).

McClaIN, Linda (2013): "A Diversity Approach to Parenthood in Family Life and Family Law", en: MCCLAIN, Linda C., y CeRE, Daniel (editores), What is Parenthood: Contemporary Debates about the Family (Nueva York-Londres, NYU Press).

MinISTERIO DE EDUCACIÓN (2018): "Hay palabras que matan: Detengamos el ciberacoso". Disponible en: http://www.haypalabrasquematan.cl [visitado el 3.12.2018].

MUÑOZ LÉ́N, Fernando (2015): "El reconocimiento legal de la transexualidad en Chile mediante el procedimiento judicial de cambio de nombre. Un caso de complementariedad epistemológica entre medicina y derecho", en: Revista Médica Chilena (№ 143), pp. 1015-1019.

(2016): "Cisnormatividad y transnormatividad como ideologías que articulan el tratamiento jurídico de la condición trans", en: Revista Austral de Ciencias Sociales ( $\left.N^{\circ} 30\right)$, pp. 161-181.

NejaIme, Douglas, y Siegel, Reva (2015): "Conscience Wars: Complicity-Based Conscience Claims in Religion and Politics", en: Yale Law Journal (Vol. 124, $\left.N^{\circ} 7\right)$, pp. 2516-2591.

Nogueira AlcalÁ, Humberto (2010): El derecho a la propia imagen. Naturaleza jurídica y sus aspectos protegidos, $1^{\text {a }}$ edición (Santiago, Editorial Librotecnia). 
Ravetllat Ballesté, Isaac (2017): “El derecho a la identidad (de género) de la infancia y la adolescencia: Del paradigma de la patología a la autodeterminación", en: Revista Actualidad Civil (№ 9), pp. 42-62.

(2018): "Igual de diferentes: la identidad de género de niñas, niños y adolescentes en Chile", en: Revista lus et Praxis (Año 24, № 1), pp. 397-436.

RAz, Joseph (2004): The Practice of Value (Oxford, Oxford University Press).

Regueiro De Giacomi, Iñaki (2012): "El derecho a la identidad de género de niñas, niños y adolescentes", en: Revista de Derechos Humanos (Año I, № 1), pp. 101-115.

Stewart, George (1992): "Interpreting the Child's Right to Identity in the U.N. Convention on the Rights of the Child", en: Family Law Quarterly (Vol. 26, $\left.\mathrm{N}^{\circ} 3\right)$, pp. 221-233.

TAYlor, Jami (2007): "Transgender Identities and Public Policy in the United States. The Relevance for Public Administration", en: Administration and Society (Vol. 39, No 7), pp. 833-856.

Toledo Jofré, María Isabel (2012): "Sobre la construcción identitaria", en: Revista Atenea (No 506), pp. 43-56.

Tórtora Aravena, Hugo (2015): "Bases constitucionales de la libertad de conciencia y culto en Chile", en: Revista de Derechos Fundamentales ( $\left.\mathrm{N}^{\circ} 7\right)$, pp. $87-115$.

UNICEF (2007): Implementation Handbook for the Convention on the Rights of the Child, $3^{\text {a }}$ edición (Ginebra, Unicef).

Vivanco Martínez, Ángela (2006): Curso de derecho constitucional, $2^{a}$ edición (Santiago, Ediciones UC), Tomo II.

YoshinO, Kenji (2007): Covering. The hidden assault on our civil rights (Nueva York, Random House).

Young, Iris (1990): Justice and the Politics of Difference (Nueva Jersey, Princeton University Press).

WeEks, Jeffrey (1993): El malestar de la sexualidad. Significados, mitos y sexualidades modernas (Traducc. Alberto Magnet, Madrid, Talasa Ediciones S.L.). (1998): Sexualidad, $1^{\text {a }}$ edición (Traducc. Mónica Mansour, Barcelona, Editorial Paidós Ibérica S.A.).

\section{NORMAS JURÍDICAS CITADAS}

Ley $N^{0} 17.344$, Autoriza el Cambio de Nombres y Apellidos en los casos que indica. Modifica Ley No 4.808, sobre Registro Civil. Diario Oficial, 22 de septiembre de 1970. 
Decreto № 830, Promulga Convención sobre los Derechos del Niño. Diario Oficial, 27 de septiembre de 1990.

Ley Antidiscriminación de la provincia de Queensland, Australia. 9 de diciembre de 1991.

Ley № 27.337, Código de los Niños y Adolescentes del Perú. 29 de diciembre de 1992.

Ley N N 1.098, Código de la Infancia y la Adolescencia de Colombia. 8 de noviembre de 2006.

\section{JURISPRUDENCIA CITADA}

Jurisprudencia nacional

M. con M (2008): Tribunal Constitucional 13 mayo 2008 (acción de inaplicabilidad) en: https://jurisprudencia.vlex.cl/vid/-58941735.

Diputados Alianza por Chile con Estado de Chile (2008): Tribunal Constitucional 18 abril 2008 (requerimiento de inconstitucionalidad) en: https://www. camara.cl/camara/media/docs/fallos/rol740.pdf.

Muñoz con Muñoz (2008): Tribunal Constitucional 29 septiembre 2009 (requerimiento de inaplicabilidad) en: https://www.tribunalconstitucional.cl/ ver2.php?id=1231.

Allamand et al. con Estado de Chile (2015): Tribunal Constitucional 1 abril 2015 (requerimiento de inconstitucionalidad) en: https://www.camara.cl/camara/ media/docs/fallos/rol2787.pdf.

Y.D.V.B. (2015): Corte de Apelaciones de Santiago 9 marzo 2015 (apelación de sentencia definitiva) en: https://oficinajudicialvirtual.pjud.cl/framelnv.php.

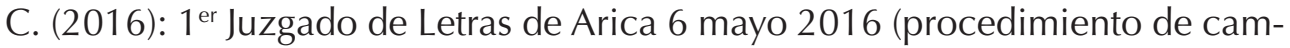
bio de nombre) en: https://oficinajudicialvirtual.pjud.cl/ADIR_7577/civil/ documentos/docuS.php?dtaDoc=FE658D1E172355A7E630C1E4C3E488EC.

S.G.L.M. y otros (2016): $1^{\text {er }}$ Juzgado de Letras Civil de Antofagasta 6 abril 2016 (procedimiento de cambio de nombre) en: https://oficinajudicialvirtual.pjud. cl/ADIR_7577/civil/documentos/docuS.php?dtaDoc=A4442C4F8BE96BA2 A343EA00C63275FE6298A95A68C416E7.

A.E.S.Z. (2016): Juzgado de Letras de Peñaflor 21 junio 2016 (procedimiento de cambio de nombre) en: https://oficinajudicialvirtual.pjud.cl/ADIR_7577/civil/ documentos/docuS.php?dtaDoc=DEFAACAFE1C2F722ECAEA15DB1622708.

O.M.C.R. y otros (2017): Corte de Apelaciones de Santiago 5 octubre 2017 (recurso de protección) en: https://oficinajudicialvirtual.pjud.cl/ADIR_7577/ 
apelaciones/documentos/docCausaApelaciones.php?valorDoc=BEA84B867 37035BDDE9B412E84EBDC708127CCDEF82EA5C8F49F43A93B2E0393.

A. G. P. con G.F.O.N. y otro (2017): Corte Suprema 19 diciembre 2017 (recurso de protección) en: https://oficinajudicialvirtual.pjud.cl/ADIR_7577/suprema/ documentos/docCausaSuprema.php?valorFile=10EA67B43E0E4BD0962824 1195BE041E.

Jurisprudencia extranjera

Tribunal Constitucional Federal Alemán, 1 BvR 2019/16, 10 de octubre de 2017. Corte IDH, OC-24/17, Solicitada por la República de Costa Rica, Identidad de Género, e lgualdad y No Discriminación a Parejas del Mismo Sexo, 24 de noviembre de 2017.

Corte Constitucional de Austria, E 2918/2016-29, 14 de marzo de 2018.

Corbiere v. Canada (Minister of Indian and Northern Affairs), [1999] 2 SCR 203, 1999 CanLII 687 (SCC).

Corte Interamericana de Derechos Humanos, Opinión Consultiva 17/2002, de 28 de agosto de 2002, Condición Jurídica y Derechos Humanos del Niño.

Corte Europea de Derechos Humanos, Application no. 35968/97, de 12 de septiembre de 2003.

Comité de los Derechos del Niño, "Observación General № 12 (2009): El derecho del niño a ser escuchado", CRC/C/GC/12.

Corte IDH, Caso Chitay Nech y otros vs. Guatemala, Serie C No 212, 25 de mayo de 2010.

Corte IDH, Caso Contreras y otros vs. El Salvador, Serie C No 232, 31 de agosto de 2011.

Corte IDH, Caso Gelman vs. Uruguay, Serie C No 221, 24 de febrero de 2011

Corte IDH, Caso Atala Riffo y Niñas vs. Chile, Serie C No 239, 24 de febrero de 2012.

Corte IDH, Caso Fornerón e hija vs. Argentina, Serie C № 242, 27 de abril de 2012.

Comité de Derechos del Niño, "Observación General Nº 14 (2013) sobre el derecho del niño a que su interés superior sea una consideración primordial (artículo $3^{\circ}$ párrafo 1)", CRC/C/CG/14.

Comité de los Derechos del Niño, "Observación General No 15 (2013): Sobre el derecho del niño al disfrute del más alto nivel posible de salud (artículo 24)", CRC/C/GC/15.

High Court of Australia, NSW Registrar of Births, Deaths and Marriages v Norrie [2014] HCA 11, 2 de abril de 2014. 
The Supreme Court of India, National Legal Services Authority v Union of India and Others 15 de abril de 2014.

Corte Constitucional de Colombia, T-476/14, 9 de julio de 2014. 